\title{
SNAP23 depletion enables more SNAP25/calcium channel excitosome formation to increase insulin exocytosis in type 2 diabetes
}

\author{
Tao Liang, ${ }^{1}$ Tairan Qin, ${ }^{1}$ Fei Kang, ${ }^{1}$ Youhou Kang, ${ }^{1}$ Li Xie, ${ }^{1}$ Dan Zhu, ${ }^{1}$ Subhankar Dolai, ${ }^{1}$ \\ Dafna Greitzer-Antes, ${ }^{1}$ Robert K. Baker, ${ }^{2}$ Daorong Feng, ${ }^{3}$ Eva Tuduri, ${ }^{2}$ Claes-Goran Ostenson, ${ }^{4,5}$ \\ Timothy J. Kieffer, ${ }^{2}$ Kate Banks, ${ }^{6}$ Jeffrey E. Pessin, ${ }^{3}$ and Herbert Y. Gaisano ${ }^{1}$ \\ 'Department of Medicine, Faculty of Medicine, University of Toronto, Toronto, Ontario, Canada. ²Department of Cellular \\ and Physiological Sciences, Faculty of Medicine, University of British Columbia, Vancouver, British Columbia, Canada. \\ ${ }^{3}$ Michael F. Price Center for Genetic and Translational Medicine, Department of Medicine and Department of Molecular \\ Pharmacology, Albert Einstein College of Medicine, Bronx, New York, USA. ${ }^{4}$ Department of Molecular Medicine and \\ ${ }^{5}$ Department of Surgery, Karolinska Institutet, Stockholm, Sweden. ${ }^{6}$ Division of Comparative Medicine, Faculty of \\ Medicine, University of Toronto, Toronto, Ontario, Canada.
}

SNAP23 is the ubiquitous SNAP25 isoform that mediates secretion in non-neuronal cells, similar to SNAP25 in neurons. However, some secretory cells like pancreatic islet $\beta$ cells contain an abundance of both SNAP25 and SNAP23, where SNAP23 is believed to play a redundant role to SNAP25. We show that SNAP23, when depleted in mouse $\beta$ cells in vivo and human $\beta$ cells (normal and type 2 diabetes [T2D] patients) in vitro, paradoxically increased biphasic glucose-stimulated insulin secretion corresponding to increased exocytosis of predocked and newcomer insulin granules. Such effects on T2D Goto-Kakizaki rats improved glucose homeostasis that was superior to conventional treatment with sulfonylurea glybenclamide. SNAP23, although fusion competent in slower secretory cells, in the context of $\beta$ cells acts as a weak partial fusion agonist or inhibitory SNARE. Here, SNAP23 depletion promotes SNAP25 to bind calcium channels more quickly and longer where granule fusion occurs to increase exocytosis efficiency. $\beta$ Cell SNAP23 antagonism is a strategy to treat diabetes.

Authorship note: TL, TQ, and FK contributed equally.

Conflict of interest: The authors have declared that no conflict of interest exists.

Copyright: () 2020, American Society for Clinical Investigation.

Submitted: April 19, 2019

Accepted: January 15, 2020

Published: February 13, 2020.

Reference information: /CI Insight. 2020;5(3):e129694.

https://doi.org/10.1172/jici.

insight.129694.

\section{Introduction}

The membrane fusion machinery requires SNARE (soluble $\underline{N}$-ethylmaleimide-sensitive factor attachment protein receptor) and $\mathrm{nSec} / \mathrm{Munc} 18$ (SM) proteins that organize the SNARE proteins into membrane fusion-ready SNARE complexes (1). Insulin secretion from pancreatic islet $\beta$ cells follows this paradigm (2-4), employing SNARE proteins vesicle-associated membrane protein 2 and 8 (VAMP2 and -8) (5, 6), syntaxins (Stx-1, -3, and -4) (7-9), and synaptosome-associated protein of $25 \mathrm{kDa}$ (SNAP25) (10-12). Whereas these different members of the VAMP and syntaxin families have been shown to mediate distinct exocytoses of insulin secretory granules (SGs) (reviewed in refs. 2-4), the SNAP25 family is less well studied. SNAP23 is the ubiquitous SNAP25 isoform that mediates exocytosis in many non-neuronal cells, such as muscle and adipocytes $(4,13)$ and pancreatic acini (14). In acini, SNAP23 on SGs and the plasma membrane (PM) (14) binds Stx-3 on SGs and PM-bound Stx-4 to form distinct SM/SNARE complexes that mediate different exocytotic events including apical and basolateral exocytosis and SG-SG fusion (15).

Peculiarly, SNAP23 is abundant in endocrine $\beta$ cells (16), and like SNAP25 binds all 4 exocytotic Stxs $(6,17)$. SNAP25 is, however, the putative SNARE partner for all syntaxins and VAMPs in mediating glucose-stimulated insulin secretion (GSIS) $(4,6,17)$, including Stx-1 and Stx-4 with VAMP2 for exocytosis of predocked SGs (SGs already docked on the PM under basal conditions, which then fuses after stimulation) (4, 7); and Stx-3 with VAMP8 for newcomer SGs (SGs not predocked on the PM under basal conditions) $(6,8)$ and SG-SG fusion $(6,8)$. Newcomer SGs are divided into short-dock (short residence 
time of $>200$ milliseconds to a few minutes at the PM before fusion) or no-dock ( $<200$ milliseconds at the PM before fusion) $(2,6,8)$. What, then, is the role of SNAP23 in $\beta$ cells? An early study in 1997 showed that overexpression of SNAP23 in insulinoma HIT-T15 $\beta$ cells treated with botulinum toxin E that cleaves SNAP25 but not SNAP23 could rescue GSIS (16). A similar study was reported in neuroendocrine PC12 cells (18). It was therefore long assumed that while SNAP25 plays the more dominant role in insulin secretion (10-12), SNAP23 simply plays a less important functionally redundant role to SNAP25 $(16,18)$. In this work, we have found that this is not the case, at least not for $\beta$ cell insulin secretion, and likely also for other secretory cells that contain abundant amounts of both SNAP25 and SNAP23.

Here, we show that deletion of SNAP23 in vivo in $\beta$ cells of mice and nonobese T2D Goto-Kakizaki (GK) rats, and in human $\beta$ cells of normal and T2D patients in vitro, resulted in paradoxically greatly increased biphasic GSIS by increasing exocytosis of both predocked and newcomer SGs, resulting in improved glucose homeostasis, which in GK rats was superior to glybenclamide treatment. This led us to propose that SNAP23, although fusion competent as tested by in vitro fusion assays $(19,20)$, in the context of $\beta$ cells plays the role of a weak partial fusion agonist (21) or an inhibitory SNARE protein (22), whereby SNAP23 depletion promotes more endogenous SNAP25 to form SNARE complexes with calcium channels (called excitosomes; ref. 23) to increase exocytosis.

\section{Results}

Generation of a mouse with $\beta$ cell-specific deletion of SNAP23. To assess the endogenous function of SNAP23 in $\beta$ cells, we generated SNAP23 ${ }^{\mathrm{fl} / \mathrm{ll}}$ mice (24). SNAP23 is abundant in pancreatic islet $\beta$ cells and $\alpha$ cells, wherein SNAP23 colocalized with insulin (Figure 1A and quantitation in Supplemental Figure 1A, bottom left; supplemental material available online with this article; https://doi.org/10.1172/jci.insight.129694DS1) and glucagon (Figure 1C and quantitation in Supplemental Figure 1A, bottom right). On single human (Figure $1 \mathrm{~B}$, first row) and mouse (Figure 1B, second row) $\beta$ cells, SNAP23 seems to be more abundant in insulin SGs and partially colocalized with Stx-1A (ref. 25; Figure 1B, third row, and quantitation in Supplemental Figure 1A, bottom middle) and SNAP25 (Figure 1B, fourth row) beneath the PM $(10,11)$. We then employed adeno-associated virus serotype 8-RIP1-Cre (AAV8-RIP1-Cre) in 8- to 10-week-old SNAP23 ${ }^{\mathrm{fl} / \mathrm{fl}}$ mice. This strategy has an additional advantage over conventional crossing of floxed mice to Cre mice in avoiding possible developmental issues. We had reported that AAV8 could deliver the target gene expression into the pancreas with high efficiency (26). The rat insulin promoter 1 (RIP1) specifically drives Cre recombinase expression in pancreatic $\beta$ cells. Two weeks after SNAP23 ${ }^{\mathrm{fl} / \mathrm{fl}}$ mice were intraperitoneally (i.p.) injected with AAV8-RIP1Cre, islets isolated from these mice showed Cre expression in $\beta$ cells with cytoplasmic insulin surrounding Cre-stained nuclei (Figure 1D, top), with no Cre expression in $\alpha$ cells (Figure 1D, bottom), confirming specific targeting of Cre to $\beta$ cells. The resulting effective deletion of SNAP23 in $\beta$ cells is shown with Cre-expressing cells devoid of SNAP23 (Figure 1E, top), and consequently the majority of insulin-positive $\beta$ cells were also devoid of SNAP23 (Figure 1E, bottom), leaving some SNAP23 staining mostly in islet periphery cells, presumably $\alpha$ cells (Figure 1D, top, and Figure 1E, top; also see Figure 1C). Finally, we assessed isolated islet protein expression (Figure $1 \mathrm{~F}$ ), showing $82.1 \% \pm 7.9 \%$ reduction in SNAP23 expression induced by AAV8-RIP1-Cre on SNAP23 ${ }^{\mathrm{f} / \mathrm{l}}$ mouse islets, with residual islet SNAP23 presumably contributed largely from $\alpha$ cells. Depletion of islet SNAP23 levels had no effects on other islet exocytotic proteins (Figure 1F and analysis of $n=3$ in Supplemental Figure 1B). Importantly, islet SNAP25 levels remained the same. To verify specific targeting of SNAP23 deletion to $\beta$ cells, we examined organs known to possess abundant SNAP23 (Figure 1G and analysis of $n=3$ in Supplemental Figure 1C), including whole pancreas (90\% acini), fat, muscle, and liver, all of which showed no reduction in SNAP23 levels or its major cognate Stx-4, VAMPs, and Munc18c 2 weeks after AAV8-RIP1-Cre injection. Because RIP1-Cre expression could leak into the brain (27), particularly the hypothalamus known to affect glucose homeostasis, we investigated and found no SNAP23 in mouse brain (thus used as negative control in Figure 1F), including the hypothalamus (Supplemental Figure 2A).

$\beta$ Cell-specific deletion of SNAP23 in mice causes paradoxical improvement in glucose homeostasis resulting from increased GSIS from pancreatic islets. AAV8-RIP1-Cre-induced deletion of $\beta$ cell SNAP23 in SNAP23 $3^{\mathrm{fl} / \mathrm{fl}}$ mice (henceforth called $\beta$ SNAP23-KO) has the advantage of comparing glucose homeostasis from the same mouse before and after viral transduction. It was initially assumed that SNAP23 plays a redundant pro-exocytotic role to SNAP25 $(16,18)$, and hence its depletion in $\beta$ cells would reduce GSIS in vivo. Instead, $\beta$ SNAP23-KO mice exhibited a paradoxical improvement in glucose homeostasis compared 
A

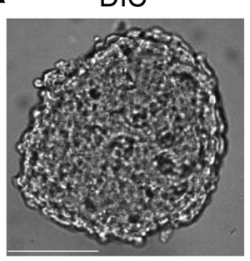

Box 1

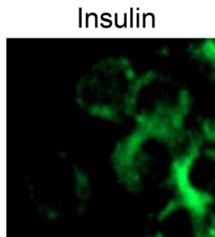

C
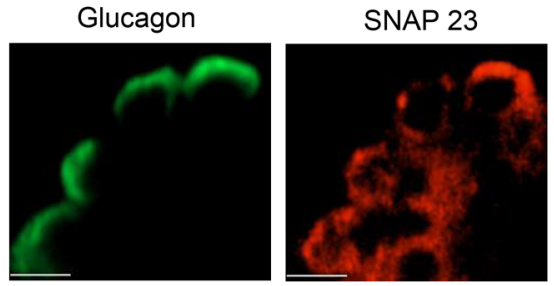

D
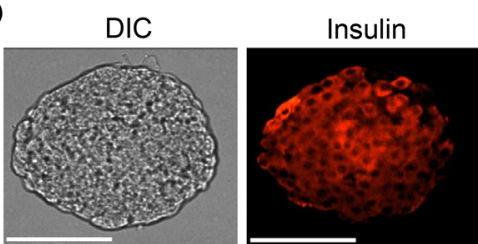

Insulin

Box 2

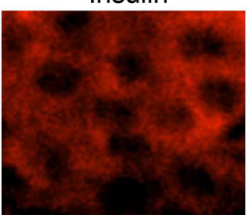

Glucagon

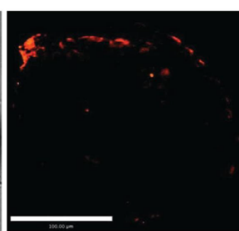

E
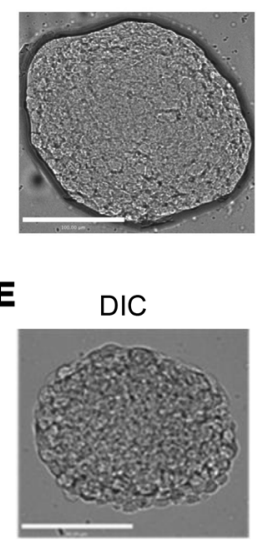

DIC

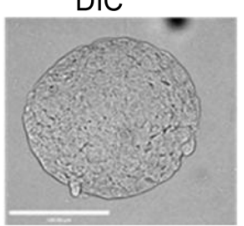

Cre

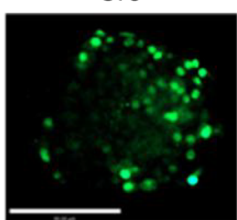

Insulin

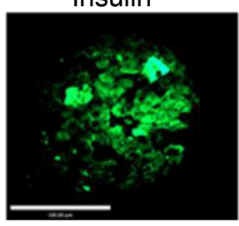

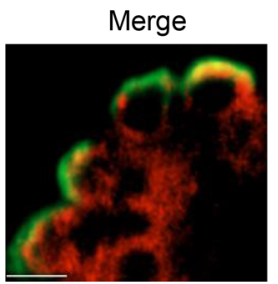
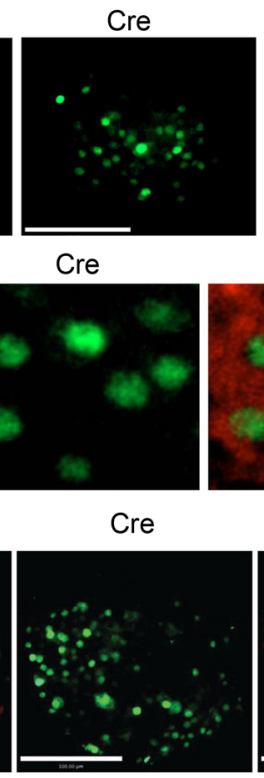

SNAP 23

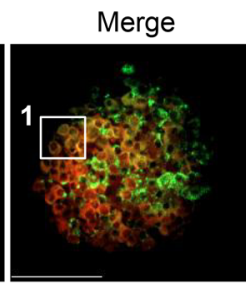

Merge

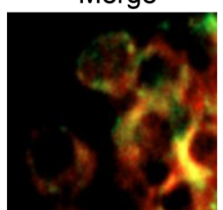

Cre

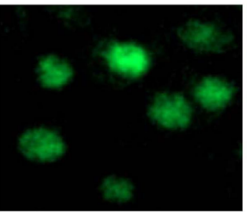

Cre

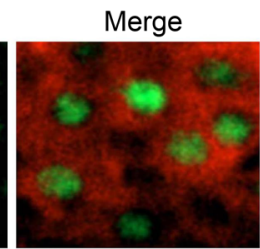

Merge

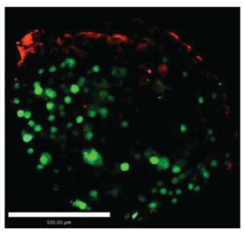

SNAP 23

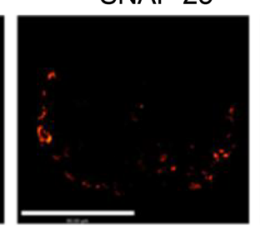

SNAP23

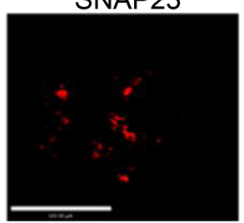

Merge

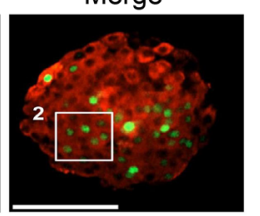

$\mathbf{F}$

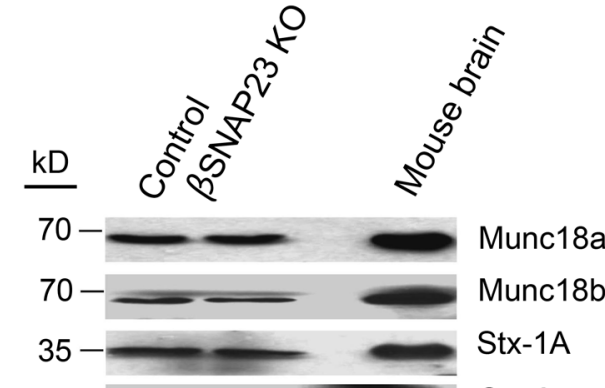

$35-\longrightarrow$ Stx-2

$35-=-$ Stx-3

$35-\ldots$ Stx-4

$25-\longrightarrow$ SNAP25

$25-\div \quad$ SNAP23

$15-\longrightarrow$ VAMP2

$15-\square$ VAMP8

$55-\longrightarrow$ Tubulin

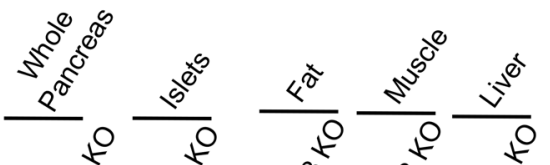

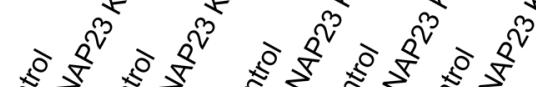

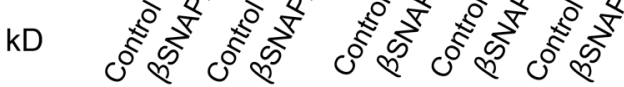

$70--\cdots=--\longrightarrow$ Munc18c

$35--\ldots-$ Stx-4

$25-\ldots \ldots$ SNAP23

$15-\square$ VAMP2

$55-\ldots \ldots-\ldots$ Tubulin 
Figure 1. Generation of a mouse with $\beta$ cell-specific deletion of SNAP23. (A) Whole islets from SNAP23 $3^{\mathrm{fl} / \mathrm{fl}}$ mice (24) show that SNAP23 is abundant in $\beta$ cells (confocal imaging), shown more clearly in the enlarged box 1. Scale bars: $100 \mu \mathrm{m}$. Quantitation can be found in Supplemental Figure 1A, bottom left. (B) Single islet $\beta$ cells from human (first row) and mouse (second row) show that SNAP23 is abundant in the insulin SGs. SNAP23 is partly colocalized with Stx-1A (third row) and SNAP25 (fourth row) on the PM. Scale bars: $5 \mu \mathrm{m}$. Quantitation can be found in Supplemental Figure 1A, bottom middle. SNAP23 antibody controls (without primary antibody) are shown in Supplemental Figure 1A, top left, and A, top right. (C) SNAP23 is also present in glucagon-containing $\alpha$ cells located in the periphery of the mouse islet. Scale bars: $10 \mu \mathrm{m}$. Quantitation in Supplemental Figure 1A, bottom right. (D) AAV8-RIP1-Cre drives Cre expression only in $\beta$ cells (top) and not in $\alpha$ cells (bottom). Scale bars: $100 \mu \mathrm{m}$. Note the cytosolic insulin surrounding the nuclear Cre shown clearly in the enlarged box 2. (E) Efficient knockdown of islet $\beta$ cell SNAP23 expression is shown in (top) where Cre-positive cells are SNAP23-negative, indicating SNAP23 deletion in those cells, and (bottom) the majority of insulin-positive cells are SNAP23-negative. The few SNAP23-positive cells are likely $\alpha$ cells. Scale bars: $100 \mu \mathrm{m}$. (F) Western blots of islets from SNAP23 $3^{\mathrm{fl} / \mathrm{fl}}$ mice injected with the AAV8 ( $\left.\beta S N A P 23-K O\right)$ or not (Control) showed reduction of SNAP23 but not other exocytotic proteins. SNAP23 and VAMP8 are not abundant in mouse brain. Blots are representative from 3 independent experiments; analysis of $n=3$ in Supplemental Figure 1B. (G) $\beta$ SNAP23-KO versus SNAP23 ${ }^{\text {fl/fl }}$ (Control) mice show SNAP23 to be reduced only in islets but not in fat, muscle, or liver, wherein SNAP23 and cognate Munc18c and Stx-4 are putative exocytotic proteins. Shown are representative of 3 independent experiments; analysis of $n=3$ in Supplemental Figure $1 C$.

with SNAP2 $3^{\mathrm{A} / \mathrm{I}}$ mice (henceforth called Control) as shown by i.p. glucose tolerance tests (IPGTTs) (Figure 2A, left), with corresponding large increases in insulin release (Figure 2A, right) encompassing first-phase ( $<30$ minutes) and second-phase ( $>30$ minutes) GSIS. In contrast, additional control (SNAP$\left.23^{\mathrm{f} / \mathrm{I}}\right)$ mice not treated with AAV8-RIP1-Cre virus monitored in parallel at 2 weeks with the virus-treated group showed no changes in glucose homeostasis (including blood insulin levels; Supplemental Figure 2B). As shown in Figure 2B, i.p. insulin tolerance tests (IPITTs) revealed no effects on insulin sensitivity, complementing our results in Figure 1G showing no reduction in SNAP23 levels in insulin-sensitive tissues. Consistently, virus-transduced $\beta$ SNAP23-KO did not affect body weight when compared with pretreatment with virus (Figure 2C) and with untreated Control mice (Supplemental Figure 2C).

We then explored whether the increased GSIS in $\beta$ SNAP23-KO mice is due to an increase in $\beta$ cell mass or increased secretory capacity of each $\beta$ cell. Between the 2 groups of mice in Figure 2, D and E, we saw no significant changes in islet number/pancreatic area (BSNAP23-KO: $2.67 \pm 0.31 \times 10^{7} \mu \mathrm{m}^{2}$; Control: $2.98 \pm 0.66 \times 10^{7} \mu \mathrm{m}^{2}$ ), islet size ( $\beta S N A P 23-K O: 37.76 \pm 5.57 \times 10^{3} \mu \mathrm{m}^{2}$; Control: $33.57 \pm 4.79$ $\times 10^{3} \mu \mathrm{m}^{2}$ ), and $\beta$ cell area/pancreatic area ( $\beta$ SNAP23-KO: $0.0059 \pm 0.0008$; Control: $0.0066 \pm 0.0009$ ). Therefore, the increased GSIS in vivo must be attributed to an increase in secretory capacity of the SNAP23-depleted $\beta$ cells.

What $\beta$ cell exocytotic events account for the increased GSIS in $\beta S N A P 23-K O$ mice? We first isolated islets from mice and conducted islet perifusion assays to assess physiologic biphasic GSIS (Figure 3A, left). Area under the curve (AUC) analysis (Figure 3A, middle) showed that $\beta$ SNAP23-KO islets exhibited increases of $144 \%$ in first-phase (BSNAP23-KO: $7.95 \pm 0.74$; Control: $3.26 \pm 0.57$ ) and $92 \%$ in second-phase (BSNAP23-KO: $5.12 \pm 0.64$; Control: $2.66 \pm 0.39$ ) GSIS over Control islets. Total islet insulin content was similar between the 2 (Figure $3 \mathrm{~A}$, right). We then employed 2 assays to assess the precise exocytotic events upregulated by SNAP23 deletion to explain these increases in biphasic GSIS.

Patch-clamp membrane capacitance $(\mathrm{Cm})$ measurements (28) with 10 serial depolarization pulses were performed to determine single $\beta$ cell exocytosis. In $\beta$ SNAP23-KO $\beta$ cells, there was a $216 \%$ increase in $\mathrm{Cm}$ compared with control $\beta$ cells (AUC analysis in Figure 3B, bottom right; $\beta S N A P 23-K O: 65.22 \pm 9.31 \mathrm{fF}$ / pF; Control: $30.05 \pm 9.37 \mathrm{fF} / \mathrm{pF})$.

To visualize the spatiotemporal mobilization of populations of SGs and single-SG fusion dynamics, we employed time-lapse total internal reflection (TIRF) microscopy of SGs tagged with neuropeptide Y-EGFP delivered by adenovirus (Ad-NPY-EGFP), as previously described $(6,8)$. In Figure $3 \mathrm{C}$, the larger increase in first-phase GSIS from $\beta$ SNAP23-KO islets seems to be mainly attributable to a $114 \%$ increase in exocytosis of predocked SGs (Figure 3C, right: $\beta S N A P 23-K O: 13.9 \pm 3.23$ events $/ 100 \mu \mathrm{m}^{2}$; Control: $6.49 \pm 1.82$ ), with no further increases in newcomer SG fusions. At basal condition (Figure $3 \mathrm{C}$, bottom right), there was, however, no significant difference in number of predocked SGs between the 2 groups ( $\beta S N A P 23-K O: 11.7 \pm 1.4 \mathrm{SGs} / 100 \mu \mathrm{m}^{2}$; Control: $11.1 \pm 0.8$ ). Our data therefore suggest that predocked SGs in $\beta$ SNAP23-KO $\beta$ cells were more fusion competent than Control $\beta$ cells. Predocked SGs, however, contribute very little to second-phase GSIS $(6,8)$. The observed increase in second-phase GSIS from $\beta$ SNAP23-KO islets is attributable to large increases in no-dock ( $\beta$ SNAP23-KO: $4.82 \pm 1.26$ events/100 $\mu \mathrm{m}^{2}$; Control: $0.7 \pm 0.39$ ) and short-dock newcomer SG fusions ( $\beta S N A P 23-K O: 5.6 \pm 2.2$ events $/ 100 \mu \mathrm{m}^{2}$; Control: $1.0 \pm 0.35$ ). SNAP23 deletion therefore increases the exocytotic efficiency of both predocked and newcomer SGs. 
A IPGTT

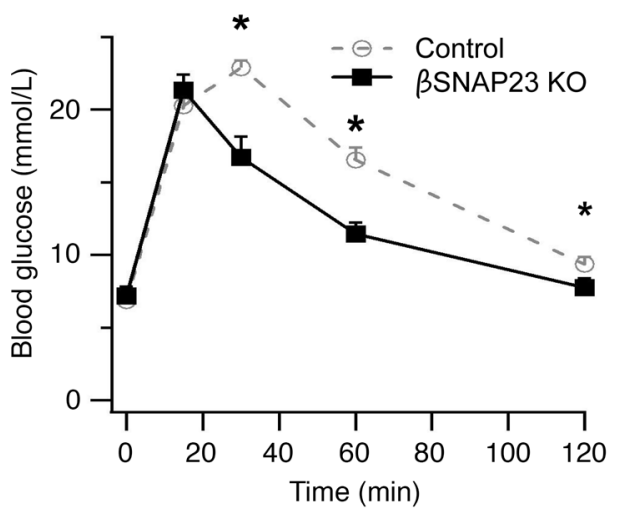

B

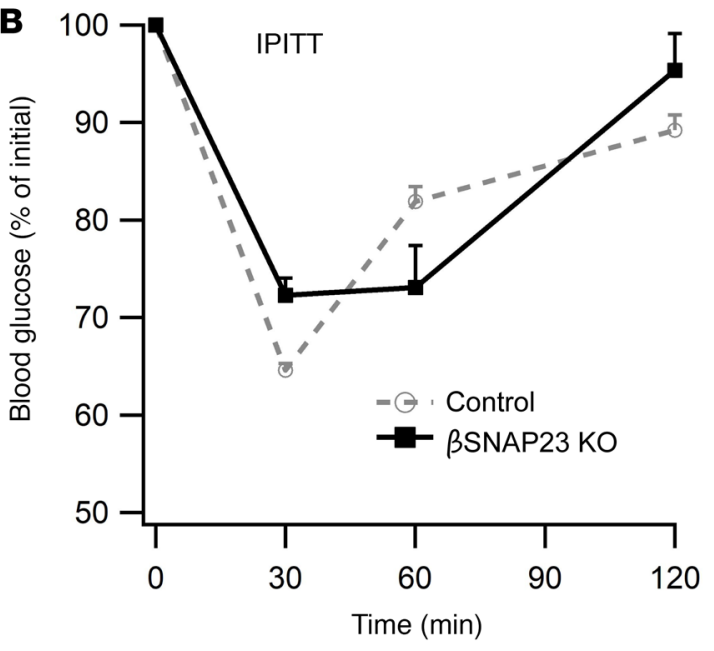

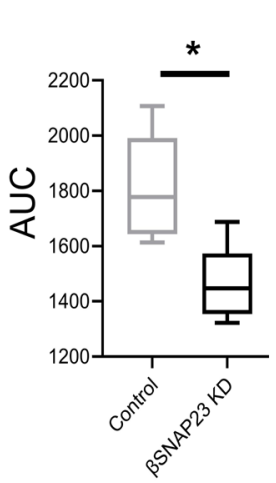

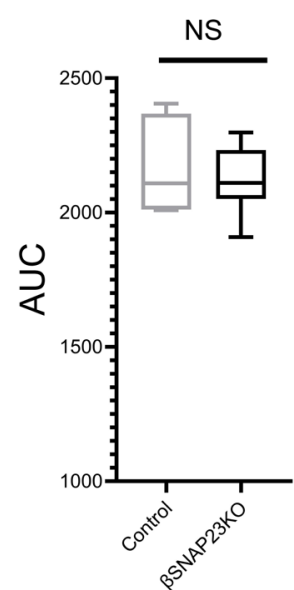

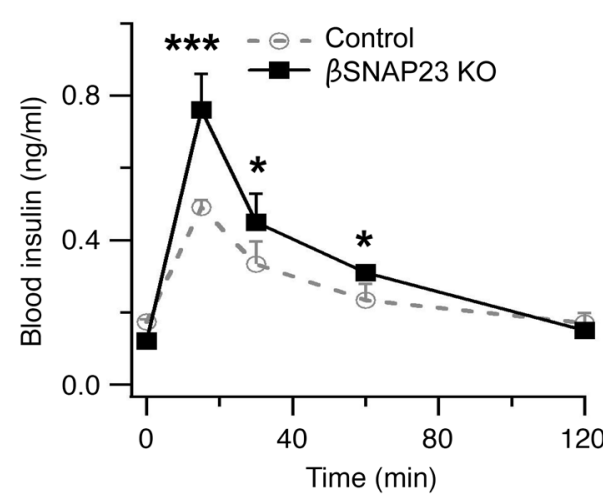

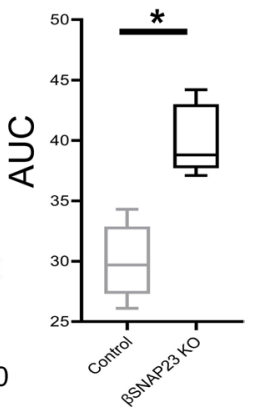

C
NS
D

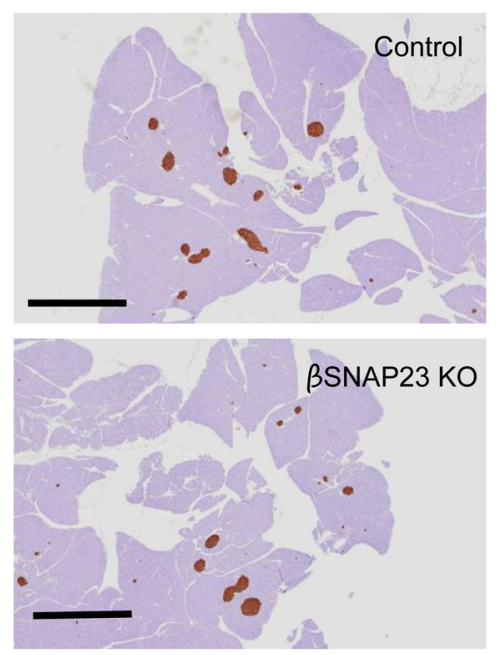

E

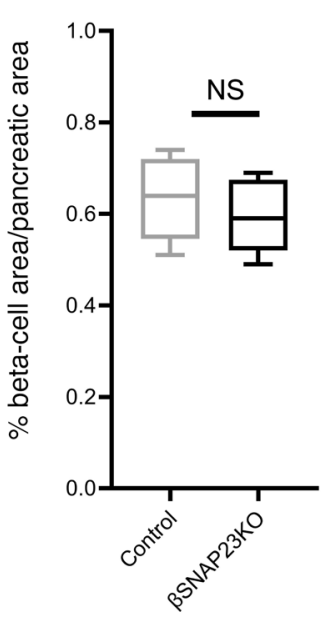

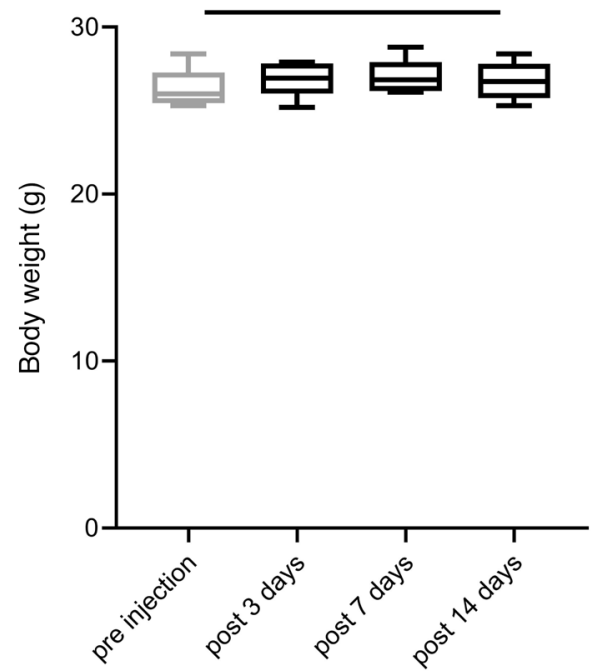
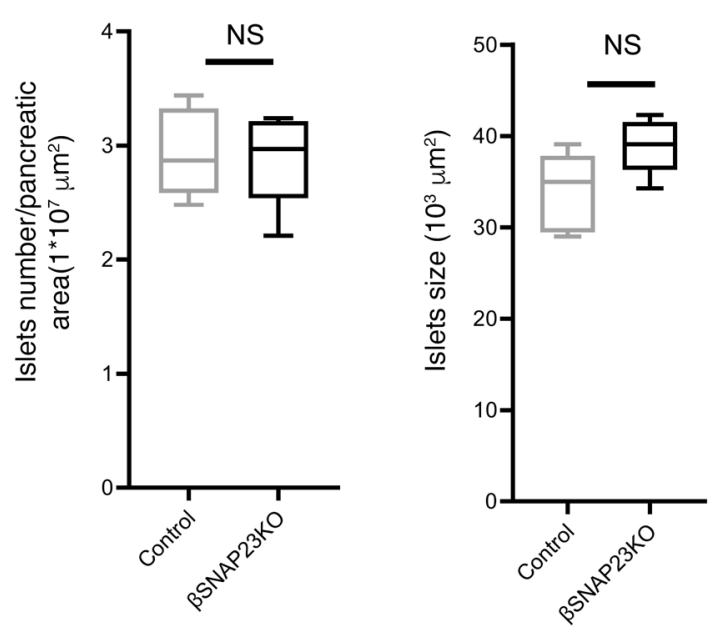

Figure 2. $\beta$ Cell-specific deletion of SNAP23 in mice improves glucose homeostasis resulting from increased GSIS from pancreatic islets. (A) IPGTT performed in the same SNAP23 ${ }^{\text {fl/fl }}$ mice before AAV8-RIP1-Cre treatment and at 2 weeks after virus treatment showed improved glucose homeostasis (left) resulting from increased insulin secretion (right). Right panels show the respective AUC analyses of $n=11$. (B) IPITT performed on the same mice before and after AAV8-RIP1-Cre treatment showed no significant changes in blood glucose levels, which indicates no effect on insulin sensitivity. Right panel shows the AUC analysis of $n=11$. (C) SNAP23-KO did not affect body weight. $n=11$. (D) Insulin-immunostained pancreatic sections (scale bars: $1000 \mu \mathrm{m}$ ), from which we conducted morphometric analysis (E), including $\beta$ cell area per pancreatic area ratios, islet number per total pancreatic area, and islet size $\left(n=12\right.$ for each group). ${ }^{*} P<0.05 ;{ }^{* *} P<0.001$. Statistical significance was assessed by 2 -tailed Student's $t$ test. 

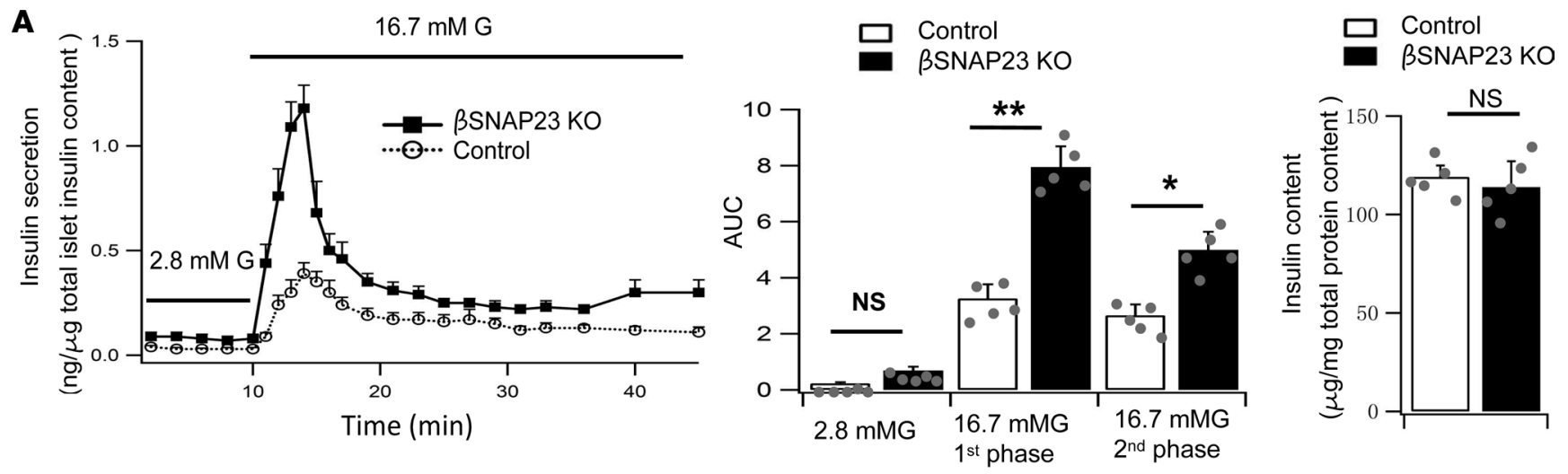

B

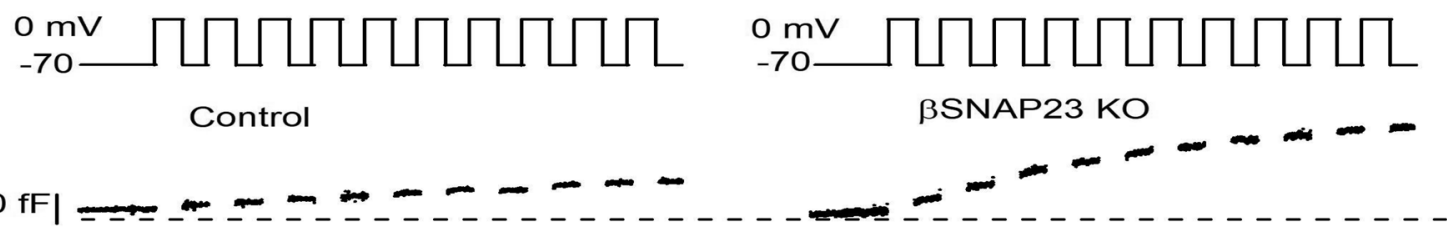

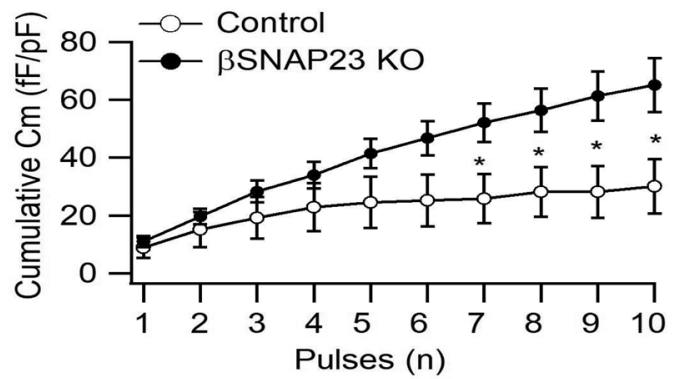

C
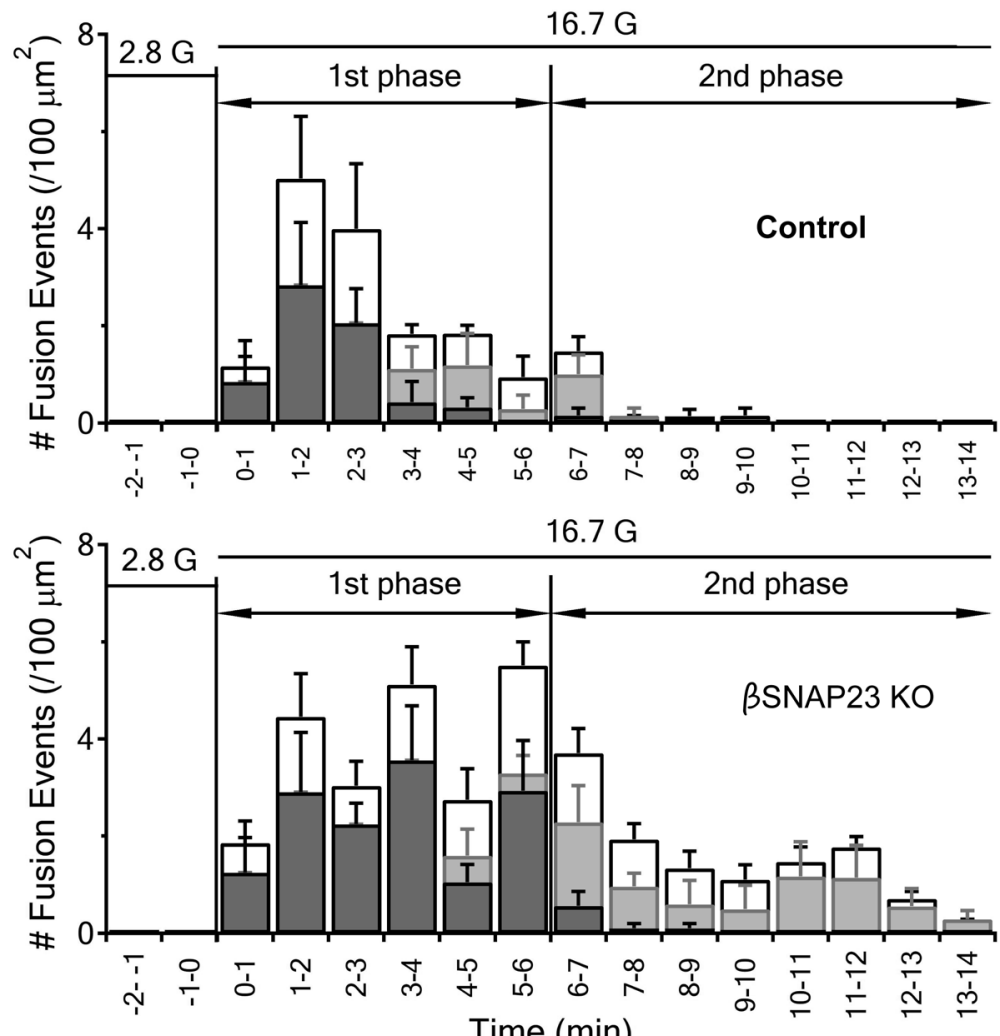

Time (min)

$\square$ pre-dock $\square$ newcomer-no dock $\square$ newcomer-short dock

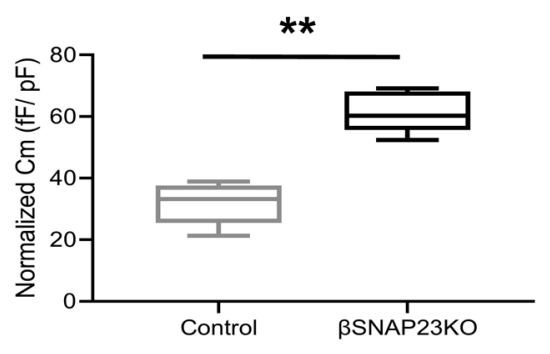

1st Phase
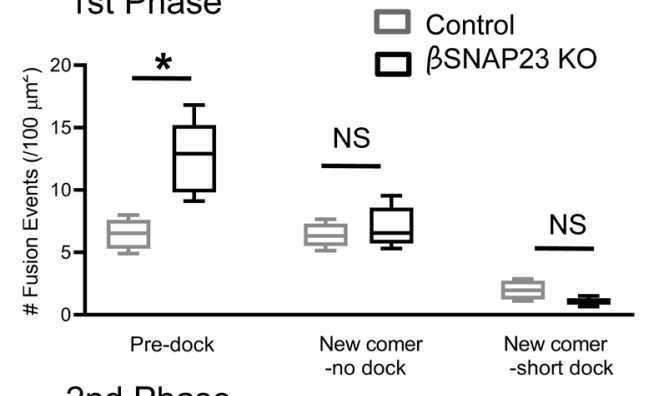

2nd Phase
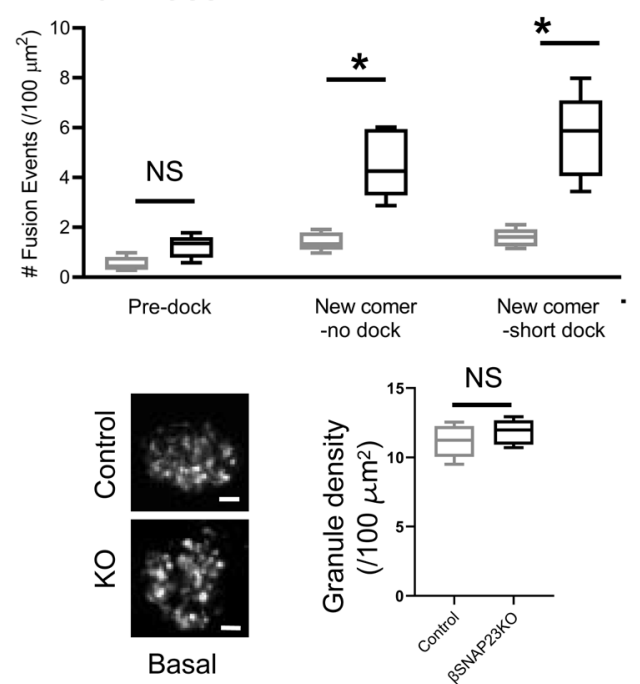
Figure 3. $\beta$ Cell exocytotic events that account for the increased GSIS in $\beta$ SNAP23-KO mice. (A) Islet perifusion assays showing that $\beta$ SNAP23-KO mouse islets exhibited enhanced first- and second-phase GSIS compared with SNAP23 ${ }^{\mathrm{fl} / \mathrm{fl}}$ (Control) mouse islets; AUC analysis shown in middle. Left: Total islet insulin content was not affected in the $\beta$ SNAP23-KO mice islets ( $n=5$ for each group). (B) Patch-clamp Cm on dispersed single $\beta$ cells of $\beta$ SNAP23-KO versus Control mice. Top shows representative recordings of exocytosis evoked by a train of ten $500-\mathrm{ms}$ depolarizations from $-70 \mathrm{mV}$ to $0 \mathrm{mV}$. Bottom left: Cumulative changes in cell capacitance normalized to basal cell membrane capacitance (fF/pF) in Control and $\beta$ SNAP23-KO $\beta$ cells, shown as (bottom right) summary graph (Control: $n=15$ cells, $\beta$ SNAP23-KO: $n=13$ cells). (C) TIRF microscopy imaging of exocytosis of predock and newcomer SGs. Left: Histograms of different fusion events in first phase (first 6 minutes after $16.7 \mathrm{mM}$ glucose stimulation) and second phase (6-14 minutes) in Control (top) versus $\beta$ SNAP23-KO $\beta$ cells (bottom). Data obtained from 3 independent experiments ( $5-6$ cells from each experiment; WT = 15 cells, $\beta$ SNAP23-KO = 16 cells). Right top: Summary of the 3 modes of fusion events in first (top) and second phases (bottom). This is the sum of the different types of SG fusion events occurring during the first phase (all frames assessed in the first 6 minutes) and second phase (6-14 minutes) normalized to the PM area. Right bottom: We also obtained TIRF microscopy images of docked insulin SGs before the stimulation (basal) above, and found no change in SG density (averaged number of SGs normalized to cell PM area on each TIRF microscopy imaging frame before stimulation) between Control versus $\beta$ SNAP23-KO $\beta$ cells (summary graph on right). Scale bars: $2 \mu \mathrm{m}$. ${ }^{*} P<0.05 ;{ }^{*} P<0.01$. Statistical significance was assessed by 2 -tailed Student's $t$ test.

SNAP23 depletion increases GSIS in normal and T2D human islets. What are the implications of these findings for human islet physiology and treatment of T2D? We depleted SNAP23 in human islets with Ad-SNAP23-shRNA/mCherry, which reduced SNAP23-positive cells to just 9\% of SNAP23-positive islet area (Figure 4A, left, Ad-scrambled shRNA/mCherry (henceforth called Control): $86 \pm 6.7 \%$; Ad-SNAP23-shRNA/mCherry (henceforth called SNAP23-knockdown [SNAP23-KD]): $7.9 \pm 3.9 \%$ ). At the islet protein level (Figure 4A, right and analysis of $n=3$ in Supplemental Figure 4A), this was an $89 \% \pm$ $5.5 \%$ reduction, and with no effects on expression of other exocytotic proteins. Remarkably, islet perifusion (Figure 4B, top) and AUC analysis (Figure 4B, bottom) showed similarly large increases of $74.2 \%$ in firstphase (SNAP23-KD: $6.48 \pm 0.33$; Control: $3.72 \pm 0.58$ ) and $114 \%$ in second-phase GSIS (SNAP23-KD: $7.89 \pm 1.1$; Control: $3.68 \pm 0.77$ ). Cm measurements (Figure $4 \mathrm{C}$ ) performed on SNAP23-KD (mCherry-positive) human $\beta$ cells showed significant increases in every depolarizing pulse (Figure $4 \mathrm{C}$, bottom left) compared with Control cells (mCherry-positive), with a cumulative increase of 200\% (SNAP23-KD: 58.42 $\pm 12.02 \mathrm{fF} / \mathrm{pF}$; Control: $29.16 \pm 6.59 \mathrm{fF} / \mathrm{pF} ; P<0.01$; Figure $4 \mathrm{C}$, bottom right).

We first assessed by electrophysiology why SNAP23-KD increases exocytosis. Because SNAP25 binds and regulates $\beta$ cell voltage-gated calcium channels $\left(\mathrm{Ca}_{\mathrm{v}} \mathrm{s}\right)(23,29)$, SNAP23 might also affect $\mathrm{Ca}_{\mathrm{v}}$ s. Supplemental Figure 3A shows that SNAP23-KD in human $\beta$ cells did not affect $\mathrm{Ca}_{\mathrm{v}}$ current. We then considered that SNAP23-KD might instead affect $\mathrm{Ca}^{2+}$ sensitivity of exocytosis, which was assessed by $\mathrm{Cm}$ increases in response to flash photolysis of caged $\mathrm{Ca}^{2+}$. This would test the hypothesis that SNAP23 could confer a reduction in fusion competence and thus become less responsive to $\mathrm{Ca}^{2+}$-mediated fusion, so SNAP23 depletion would relieve more fusion-competent SNAP25 molecules to more effectively mediate fusion. Flash photolysis of $o$-nitrophenyl-caged EGTA (NP-EGTA) was used to induce a step-like, homogeneous increase in intracellular $\mathrm{Ca}^{2+}$ concentration $\left[\mathrm{Ca}^{2+}\right]_{\mathrm{i}}$ from 200-300 nM to 5-10 $\mu \mathrm{M}$. Averaged Cm traces were compared between control and SNAP23-KD cells responding to similar step-like $\left[\mathrm{Ca}^{2+}\right]_{i}$ elevations (Supplemental Figure 3B, top). At low $\left[\mathrm{Ca}^{2+}\right]_{\mathrm{i}}$ elevation $(<10 \mu \mathrm{M})$, there is a fast component that releases earlier than the readily releasable pool, referred to as the highly calcium-sensitive pool (HCSP) (30), which occurs within $200 \mathrm{~ms}$ after the flash spike (Supplemental Figure 3B, middle). Curve-fitting analysis of the multiple components of $\mathrm{Cm}$ increases demonstrates that SNAP23 deletion neither changed the kinetics of secretory response nor affected the size and release rate of the HCSP. To confirm, whole-cell capacitance change recorded during direct application of $200 \mathrm{nM}$ or $1.5 \mu \mathrm{M}$ free $\mathrm{Ca}^{2+}$ via patch pipette showed that SNAP23-KD also did not affect exocytosis (Supplemental Figure 3B, bottom).

Human T2D islets were reported to exhibit reduced levels of some SNARE and SM proteins (31) (primarily Stx-1A, VAMP2, SNAP25, and Munc18a) to explain the insulin secretory deficiency in T2D, particularly the loss of first-phase release. Figure 5A (analysis of $n=3$ in Supplemental Figure 4B) confirms that although SNAP25, cognate Stx-1A, and Munc18a levels are severely reduced in T2D human islets (31), SNAP23 levels are normal. Levels of Stx-3 (8), which mediate newcomer SGs in second-phase GSIS, and Stx-4, which plays a role in both first- and second-phase GSIS $(4,9)$, were unaffected. SM protein Munc18b, which binds Stx-3, also showed reduced levels, as we have recently reported (32). Because reduction in $\beta$ cell SNAP23 levels potentiated GSIS when levels of other exocytotic proteins are normal (Figure 4, A-C), we asked the question whether SNAP23 depletion of T2D islets could rescue the deficient GSIS. We treated the T2D human islets with Ad-SNAP23-shRNA/mCherry versus Ad-scrambled shRNA/mCherry (Control) and conducted islet perifusion assays (Figure 5B). As is well known, GSIS from T2D human islets is much 
A

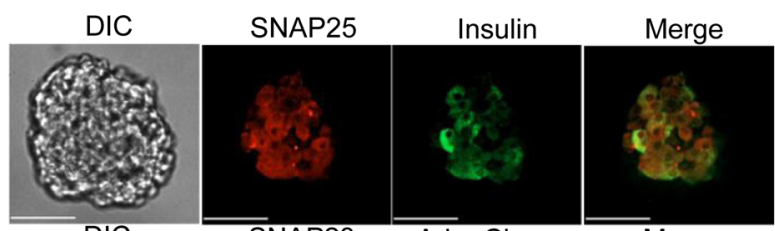

DIC

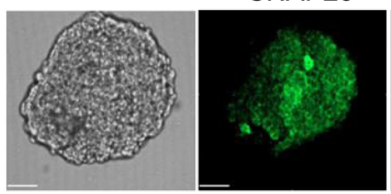

DIC
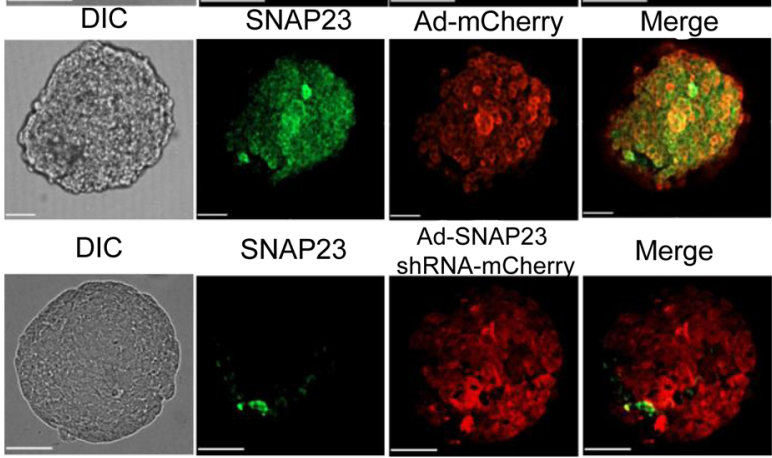

Merge
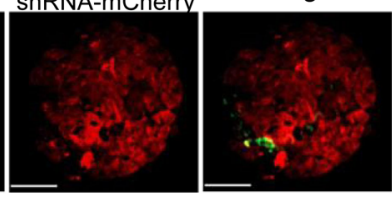

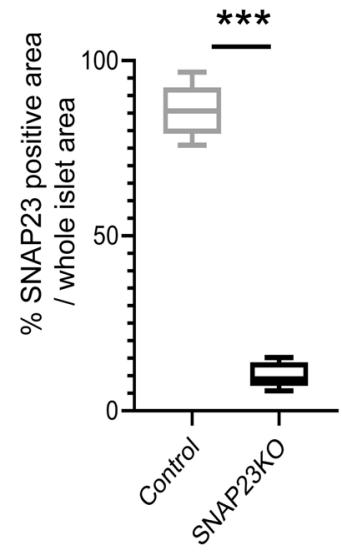

C

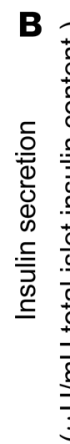
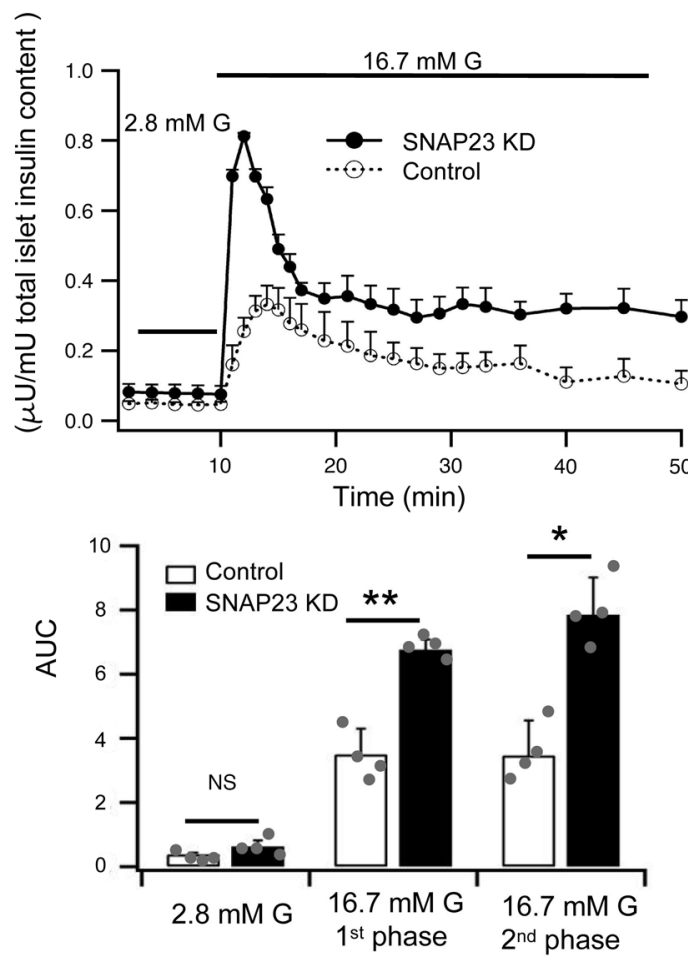

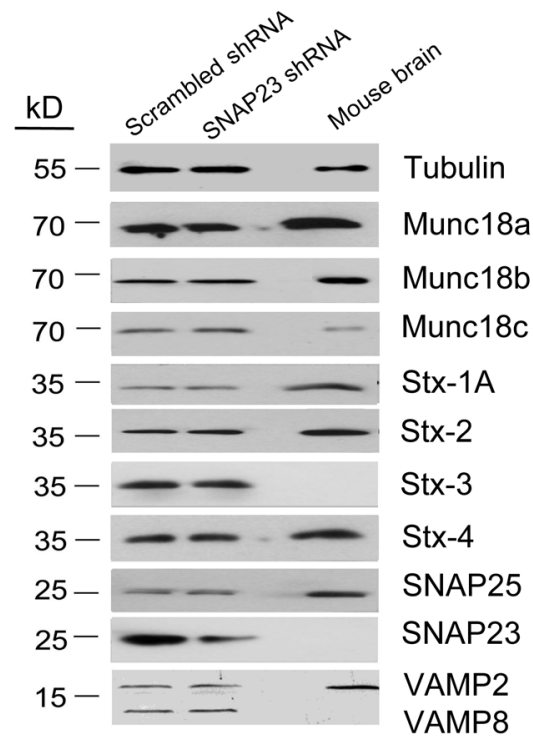

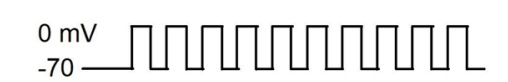

Control

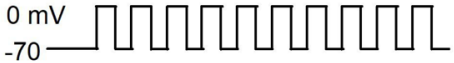

$-70 \longrightarrow-4$
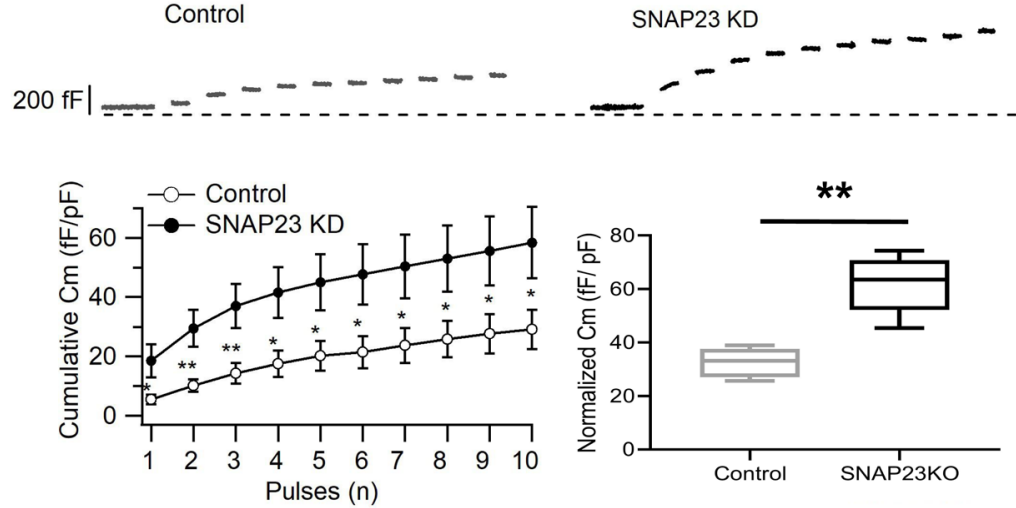

Figure 4. SNAP23 depletion increases GSIS in normal human islets. (A) Ad-SNAP23 shRNA/mCherry treatment (48 hours) of human islets (see Supplemental Table 1 for details on human donors) effectively depleted SNAP23 (SNAP23-KD) as shown on confocal imaging (left) and islet protein levels (right). Scale bars: $100 \mu \mathrm{m}$. Left: SNAP23 is abundant in human islet $\beta$ cells (top) and not affected by Ad-scrambled shRNA/mCherry (middle). SNAP23 was severely depleted by Ad-SNAP23 shRNA/mCherry treatment (bottom), wherein the few SNAP23-positive cells are mCherry-negative, allowing calculation of the ratio of SNAP23-positive area per islet area (right graph, $n=19$ islets from each group). Right: Western blots of islets show reduction in SNAP23 protein levels by Ad-SNAP23 shRNA/ mCherry but no effects on the other exocytotic proteins. Shown are representative of 3 experiments, with analysis of $n=3$ in Supplemental Figure $4 \mathrm{~A}$. (B) SNAP23-KD of human islets increased first- and second-phase GSIS compared with Ad-scrambled shRNA/mCherry-treated (Control) islets. AUC analysis in bottom from $n=4$ for each group, from 4 independent experiments. (C) These human islets were then dispersed into single cells for patch-clamp Cm measurements performed on mCherry-positive $\beta$ cells, which showed that SNAP23-KD $\beta$ cells exhibited increased exocytosis. Top: Representative recordings. Bottom left: Cumulative changes in cell capacitance normalized to basal cell membrane capacitance (fF/pF) in Control versus SNAP23-KD ( $n=15$ cells) $\beta$ cells, and shown as (bottom right) summary graph (Control: $n=14$ cells, SNAP23-KD: $n=15$ cells). ${ }^{*} P<0.05$; ${ }^{* *} P<0.01$; ${ }^{* *} P<0.001$. Statistical significance was assessed by 2-tailed Student's $t$ test.

reduced in both first- and second-phase GSIS (32). Remarkably, SNAP23 depletion of T2D human islets increased first-phase GSIS by 89\% (AUC analysis, Figure 5B, bottom; SNAP23-KD: $2.64 \pm$ 0.57; Control: $1.4 \pm 0.25$ ) and second-phase GSIS by $103 \%$ (SNAP23-KD: $2.4 \pm 0.28$; Control: $1.18 \pm 0.19$ ), to levels approaching the GSIS of normal human islets (Figure 4B). 
A

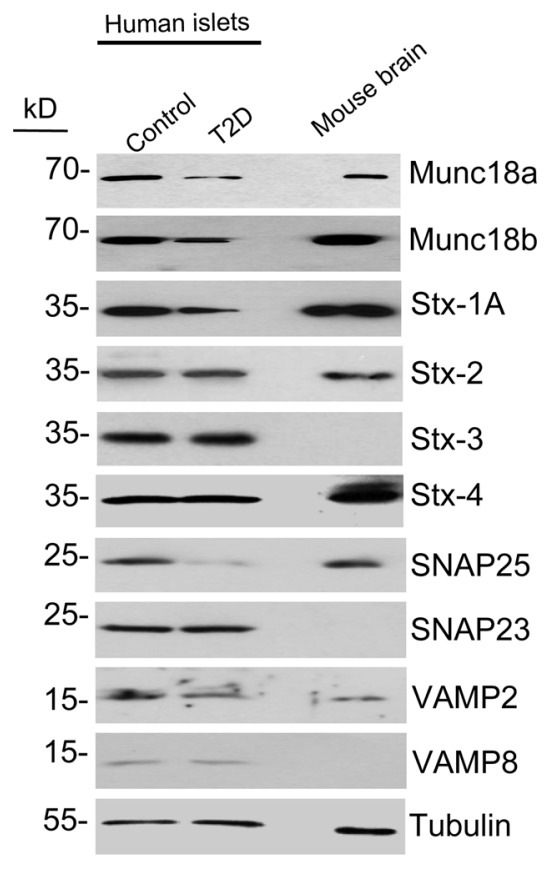

B Human T2D islets
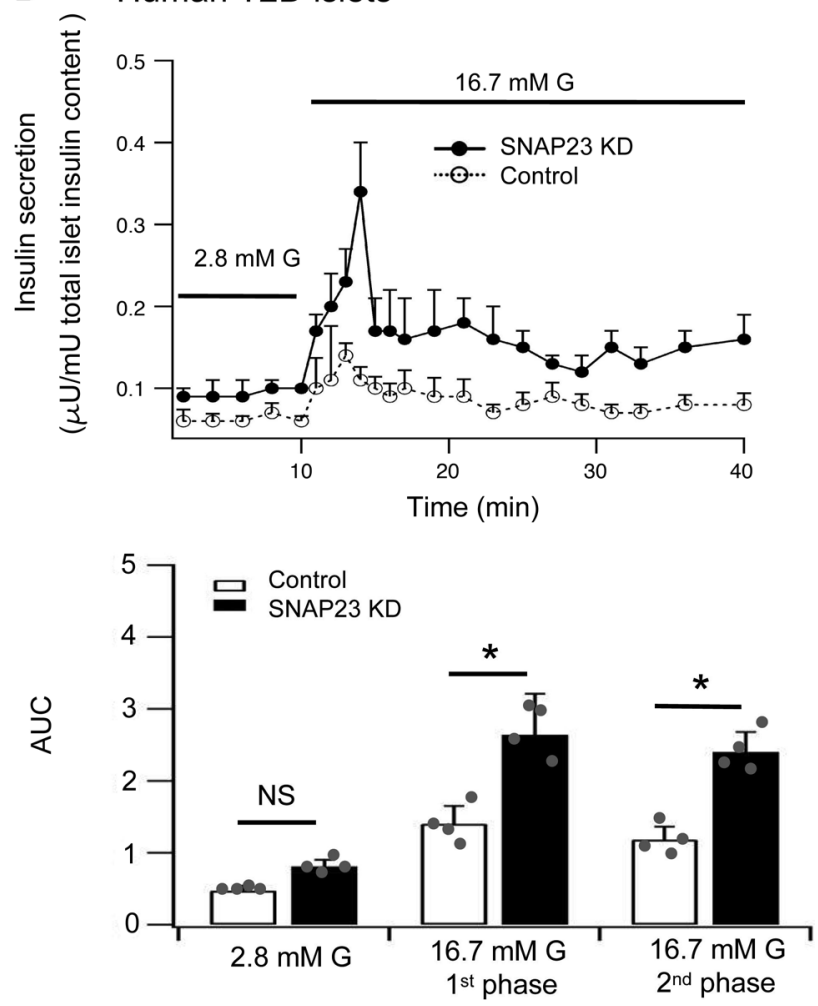

Figure 5. SNAP23 depletion increases GSIS in T2D human islets. (A) Western blots of T2D human islets (see Supplemental Table 1 for T2D patients' donor information) show reduction of Stx-1A and SNAP25 as previously reported (24), but with normal levels of SNAP23 and several other syntaxins. Shown are representative of 3 experiments with analysis of $n=3$ in Supplemental Figure 4B. (B) Ad-SNAP23 shRNA/mCherry treatment to deplete SNAP23 in T2D human islets increased first- and second-phase GSIS compared with Ad-scrambled shRNA/mCherry (Control)-treated T2D islets. $n=4$ for each group, from 4 independent experiments. ${ }^{*} P<0.05$. Statistical significance was assessed by 2-tailed Student's $t$ test.

We performed the converse experiment in which SNAP23 was overexpressed in normal human islets with Ad-SNAP23/mCherry and obtained a moderate increase of $269.3 \% \pm 19.2 \%$ of normal islet levels, which did not affect the expression of other exocytotic proteins (Figure 6A and analysis of $n=3$ in Supplemental Figure 4C), but was able to cause a $49.2 \%$ reduction in first-phase GSIS (SNAP23 overexpression: $2.13 \pm 0.93$; Control: $4.19 \pm 0.87$; Figure $6 \mathrm{~B}$, top, and AUC analysis of $n=3$ in Figure 6B, bottom) and $48.9 \%$ reduction in second-phase GSIS (SNAP23 overexpression: $1.56 \pm 0.87$; Control: $3.05 \pm 0.8$ ). Supplemental Figure 4D confirms that the overexpressed SNAP23-mCherry in human $\beta$ cells surfaced to its native location in the PM (phalloidin stain) where Stx-1A is abundant, and also colocalized with Stx-3 that is abundant in insulin SGs, and not trapped in the Golgi complex. TIRF microscopy assay of single-SG fusion dynamics (Figure 6C, top) showed that the decrease in first-phase GSIS was attributable to a $50.1 \%$ reduction in exocytosis of predocked SGs (Figure 6C, bottom, SNAP23 overexpression: 2.83 \pm 0.82 events $/ 100 \mu \mathrm{m}^{2}$; Control: $5.67 \pm 0.74$ ) and newcomer SGs, including a $59.5 \%$ reduction in no-dock SGs (SNAP23 overexpression: $3.44 \pm 0.95$; Control: $8.5 \pm 2.49$ ) and 90\% reduction in short-dock SGs (SNAP23 overexpression: $0.26 \pm 0.05$; Control: $2.58 \pm 0.52$ ). The decrease in second-phase GSIS caused by SNAP23 overexpression was attributable to a $55.8 \%$ reduction in no-dock newcomer SGs (Figure $6 \mathrm{C}$, bottom; SNAP23 overexpression: $5.13 \pm 0.49$; Control: $11.6 \pm 2.92$ ) and $61.8 \%$ reduction in short-dock newcomer SGs (SNAP23 overexpression: $2.54 \pm 0.82$; Control: $6.65 \pm 1.86$ ).

Pancreatic SNAP23 depletion in T2D GK rats rescues insulin secretory deficiency, restoring glucose homeostasis. What is the implication of pancreatic islet SNAP23 depletion for restoring glucose homeostasis in T2D? GK rats, a well-established nonobese T2D model closely mimicking human T2D (32), exhibit reduced biphasic GSIS with normal peripheral tissue sensitivity to insulin, and which like human T2D (31), has been attributed in part to severely reduced islet levels of SNARE proteins that mediate predocked SG exocytosis $(33,34)$. We infused Ad-SNAP23-shRNA/mCherry versus Control Ad-scrambled shRNA/mCherry into T2D GK rats via pancreatic duct $(32,35)$ (Figure 7$)$. In a subset of GK rats, islets were isolated immediately after virus 
A

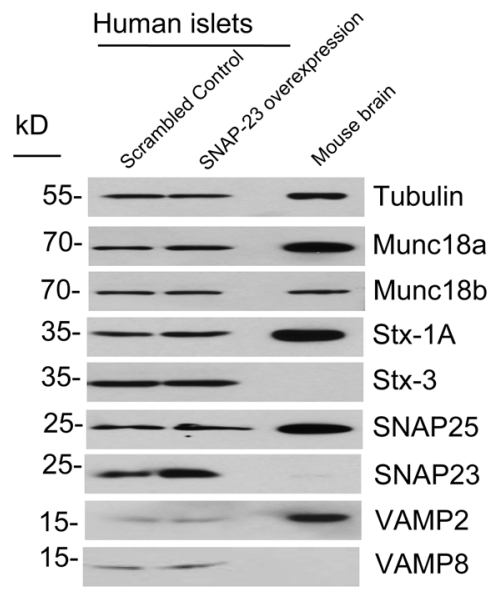

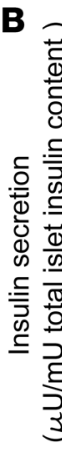

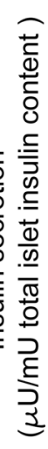

0.5

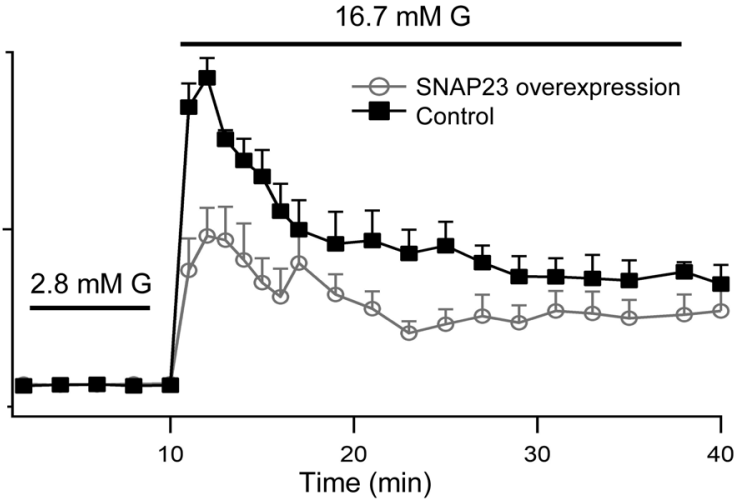

Control

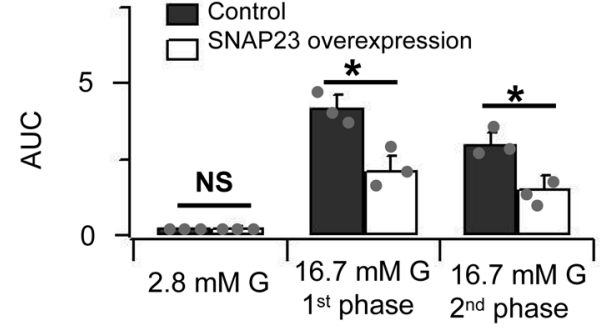

C
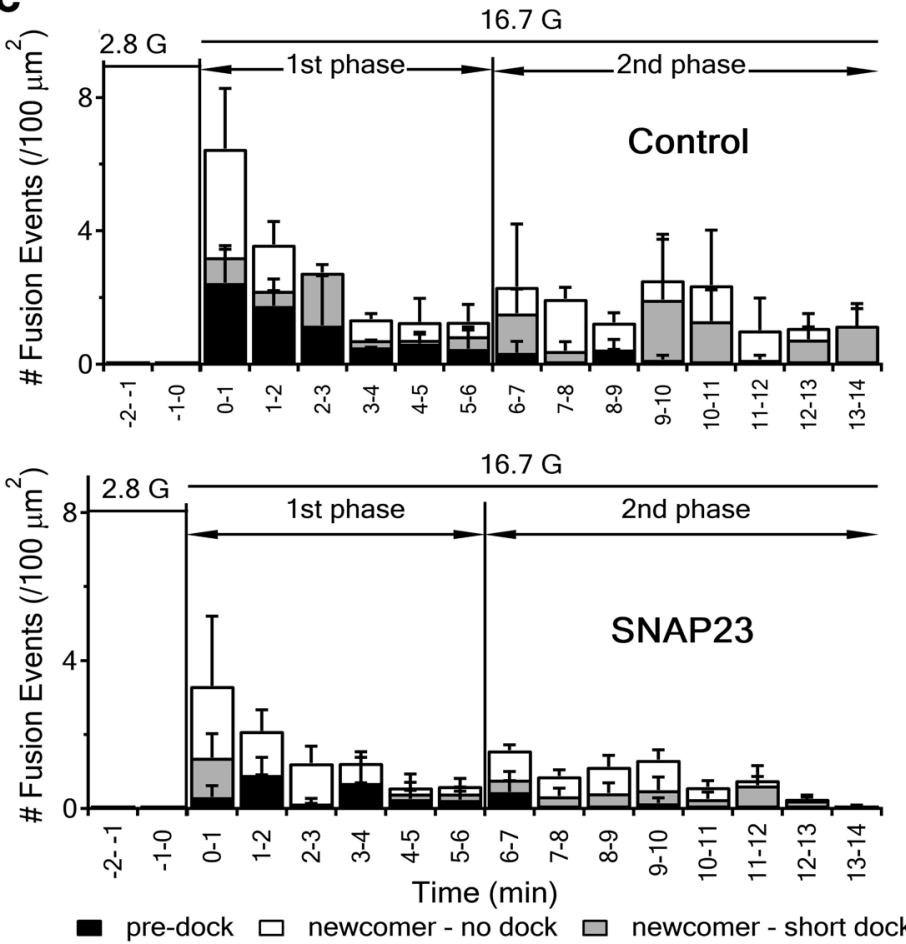

$\square$ Control

1st Phase

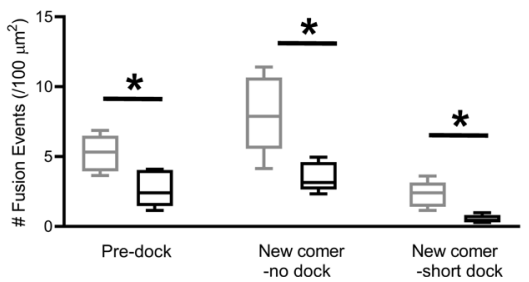

2nd Phase

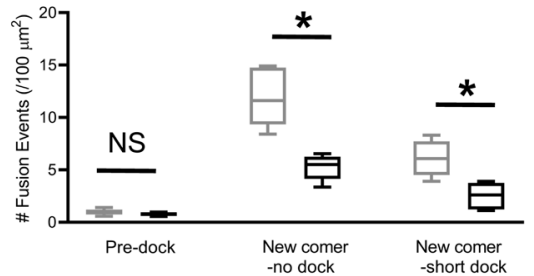

Figure 6. SNAP23 overexpression inhibits GSIS in normal human islets and $\beta$ cells. (A) Ad-SNAP23/mCherry treatment (48 hours) of human islets effectively overexpressed SNAP23 as shown on Western blots with no effects on other exocytotic proteins. Shown are representative of 3 experiments with analysis of the $n=$ 3 in Supplemental Figure 4C. (B) Islet perifusion assays showing that SNAP23 overexpression in human islets decreased first- and second-phase GSIS. AUC analysis of $n=3$ from 3 independent experiments shown in bottom. (C) TIRF microscopy imaging of exocytosis of predock and newcomer SGs. Top: Histograms of different fusion events in first-phase (first 6 minutes after $16.7 \mathrm{mM}$ glucose stimulation) and second-phase (6-14 minutes) in Control versus SNAP23 overexpressing $\beta$ cells. Data obtained from 3 independent experiments ( $5-6$ cells from each experiment; control $=14$ cells, SNAP23 overexpression $=15$ cells). Bottom: Summary of the 3 modes of fusion events in first and second phases. ${ }^{*} P<0.05$. Statistical significance was assessed by 2-tailed Student's $t$ test. 
infusion and cultured for 3 days to allow shRNAs to work optimally. Ad-SNAP23-shRNA/mCherry-infused GK rat islets showed a $68.4 \%$ reduction (Supplemental Figure 5A) in SNAP23 levels; otherwise untreated GK rat islet SNAP23 levels were similar to Wistar rat islets. Islet levels of predocked SG exocytotic proteins (Munc18a, Stx-1A, SNAP25, and VAMP2) in GK rats were confirmed to be severely reduced (Supplemental Figure 5A and refs. 33, 34), and newcomer SG exocytotic proteins Stx-3 (8), VAMP8 (6), and Munc18b (32) were not affected by SNAP23 depletion, consistent with the results of the $\beta$ SNAP23-KO mouse (Figure 1) and human islet SNAP23 depletion (Figure 4). Taken together, these results indicate that the resultant increased GSIS in vivo in GK rats depleted of islet SNAP23 (Figure 7), as with $\beta$ SNAP23-KO mice (Figures 2 and 3) and human islets SNAP23-KD (Figures 4 and 5), were due to $\beta$ cell SNAP23 depletion per se and not attributable to any effect on levels of other exocytotic proteins.

In fact, just 1 week after pancreatic ductal infusion with Ad-SNAP23-shRNA/mCherry into GK rats, IPGTT already displayed improved glycemic control, with a corresponding increase in insulin secretion (compared with Ad-mCherry in Figure 7A and compared with Ad-mCherry and before infusion in Supplemental Figure 5B). This improvement approached normoglycemia, peaking at 2 weeks after infusion (Figure 7B), persisted at 4 weeks after infusion (Figure 7C), but becoming less so at 8 weeks after infusion (Figure 7D) due to reduced adenovirus expression at 8 weeks $(32,35)$. Control virus-treated (Ad-Cherrytreated) GK rats were similarly hyperglycemic at 1 and 2 weeks after infusion (Figure 7, A and B) as the preop state (Supplemental Figure 6, A and B), and displayed worsening hyperglycemia at 4 and 8 weeks after infusion (Figure 7, C and D, and Supplemental Figure 6, C and D), with corresponding progressive reduction in blood insulin levels. Insulin tolerance tests (ITTs) (Supplemental Figure 5C) showed slight worsening of insulin resistance of GK rats at 10 weeks after infusion compared with the pre-op normal insulin tolerance of GK rats, but there was no difference between Ad-SNAP23-shRNA/mCherry and control virus treatments, suggesting that the increased insulin resistance was likely attributable to postoperative stress.

We compared the effects of Ad-SNAP23shRNA/mCherry pancreatic ductal infusion treatment of GK rats to a standard treatment for $\mathrm{T} 2 \mathrm{D}$, which is oral gavage with a long-acting sulfonylurea glybenclamide at the optimal dose of $2 \mathrm{mg} / \mathrm{kg}$ (ref. 36 and Figure 7). Whereas glybenclamide treatment was superior to vehicle treatment (Supplemental Figure 6), there was progressive reduction in glybenclamide-stimulated insulin release with corresponding worsening of glycemic control. In contrast, Ad-SNAP23-shRNA/mCherry treatment was initially equal to glybenclamide treatment at 1 week after infusion (Figure 7A), and then became superior at 2 weeks after infusion (at peak response), which persisted at 4 and 8 weeks after infusion in stimulating insulin release, with corresponding improved glycemic control (Figure 7, B-D). At 8 weeks after infusion (Figure 7D), showing overall reduced insulin secretion from all groups, the Ad-SNAP23-shR$\mathrm{NA} / \mathrm{mCherry}$ group still showed GSIS that was $108 \%$ greater than the control virus group compared with a 42\% increase in the glybenclamide group (AUC: Ad-SNAP23-shRNA/mCherry: 85.2 9.1; Ad-mCherry: $40.9 \pm 5.5$; glybenclamide: $60.1 \pm 4.9$ ), and with corresponding superior glycemic control.

Some of these rats were sacrificed after IPGTT, and the pancreases then resected for histological analysis (Supplemental Figure 5D). $\beta$ Cell mass and distribution in GK rat islets with or without SNAP23 depletion were very similar compared with those of pancreases before infusion. This indicates that the large increase in insulin output caused by SNAP23 depletion versus the smaller output from glybenclamide treatment was due to increased insulin secretion per $\beta$ cell and not by any changes in $\beta$ cell mass or islet morphology.

SNAP23 depletion enables endogenous SNAP25 to promote formation of more fusion-competent fusion complexes. We explored for a possible mechanism to explain the increase in insulin SG exocytosis caused by SNAP23 depletion by performing protein-binding studies to assess SM/SNARE complexes formed with SNAP23 and SNAP25. INS-832/13 cells were used instead of islets, as this provides an abundance of proteins required for this assay. In Figure 8A, anti-SNAP23 antibody pulled down from INS-832/13 cells the same 3 exocytotic SM/SNARE complexes that interact with SNAP25 $(4,6,17)$, including Munc18a/Stx-1A/VAMP2, Munc18b/Stx-3/VAMP8, and Munc18c/Stx-4/VAMP2, and several proteins within these complexes increased with $16.7 \mathrm{mM}$ glucose plus $10 \mathrm{nM}$ glucagon-like peptide 1 (GLP-1) stimulation (analysis in Supplemental Figure 7A). When SNAP23 levels were reduced by $83 \%$ with Ad-SNAP23-shRNA/mCherry, the resulting SM/SNARE complexes pulled down with anti-SNAP25 antibody were increased (Figure 8B), particularly including those SM/SNARE complexes Munc18a/Stx-1A/VAMP2 and Munc18b/Stx-3/VAMP8 that mediate exocytosis of predocked SGs and newcomer SGs $(2,6,17)$, respectively (analysis in Supplemental Figure 7B). Munc18c and Stx-4 levels were not increased (data not shown). These results suggest that SNAP23 may be competing with SNAP25 (and vice versa) to form complexes with these cognate SNARE proteins. 

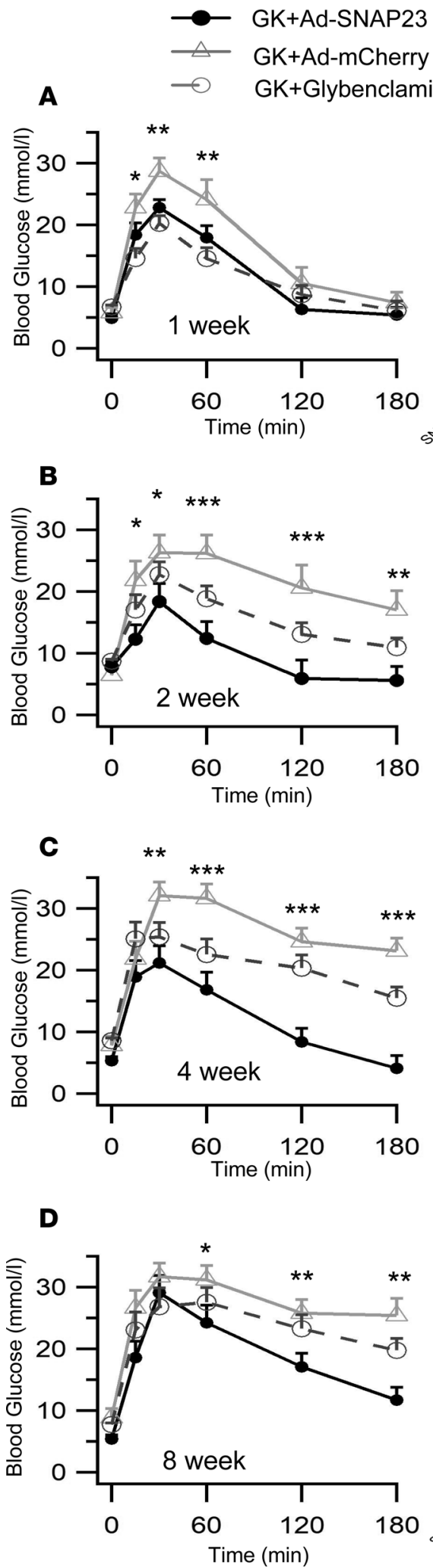
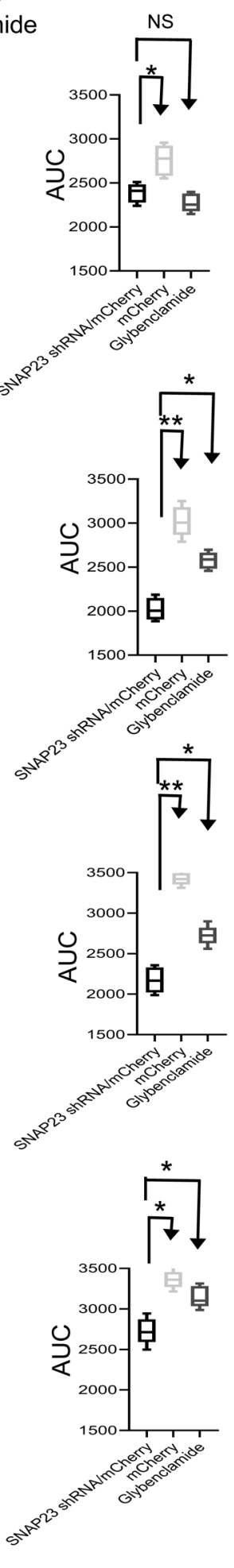
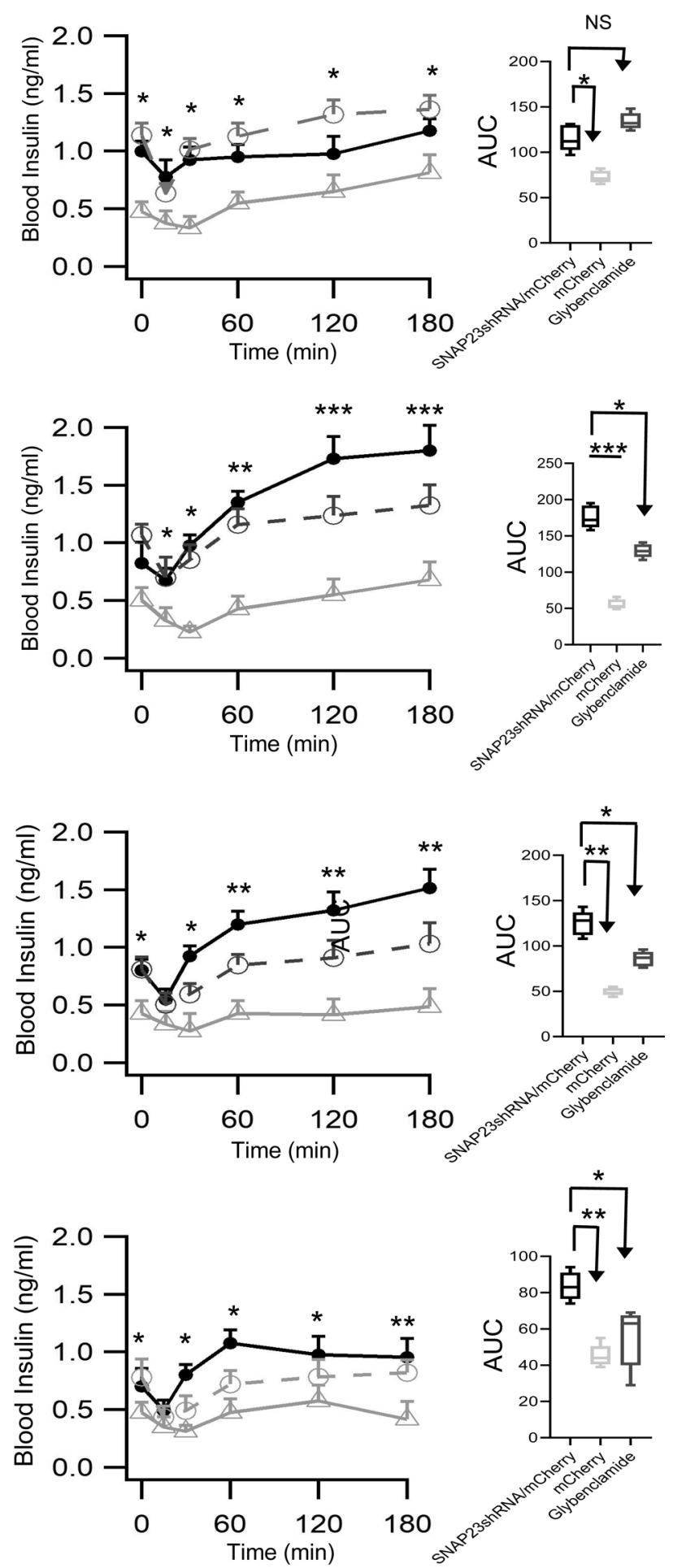

Figure 7. Pancreatic SNAP23 depletion in type-2 diabetic GK rats rescues insulin secretory deficiency and restores glucose homeostasis. Ad-SNAP23 shRNA/ $\mathrm{mCherry}\left(6.6 \times 10^{9} \mathrm{PFU}\right)$ versus Ad-mCherry (same dose) was infused via pancreatic duct into CK rats. IPGTTs (blood glucose and insulin levels obtained) were performed after infusion at 1 (A), 2 (B), 4 (C), and 8 weeks (D). Glybenclamide treatment of age- and sex-matched GK rats as conventional treatment for T2D was also performed; IPGTT was then performed at the same time points. Graphs on the right show AUCs encompassing 180 minutes of the IPCTTs. Glybenclamide group: $n=6$ and Ad-SNAP23 shRNA/mCherry group: $n=6$ for 1,2 , and 4 weeks after infusion, and $n=5$ for 8 weeks after infusion. Ad-mCherry control groups: $n=6$ for 1 and 2 weeks after infusion, and $n=5$ for 4 and 8 weeks after infusion. We also performed vehicle control in GK rats compared with glybenclamide treatment, and conducted IPGTTs as shown in Supplemental Figure 6. ${ }^{*} P<0.05 ;{ }^{* *} P<0.01 ;{ }^{* * *} P<0.001$. Statistical significance was assessed by repeated-measures ANOVA. 
A

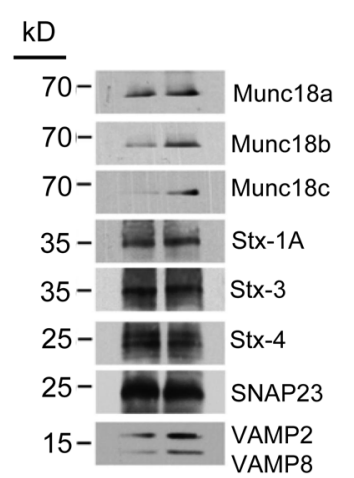

Glucose (mM) $\quad 0.8 \quad 16.7$

GLP-1(10nM) $\frac{0 \quad 10}{\text { SNAP23 IP }}$

C
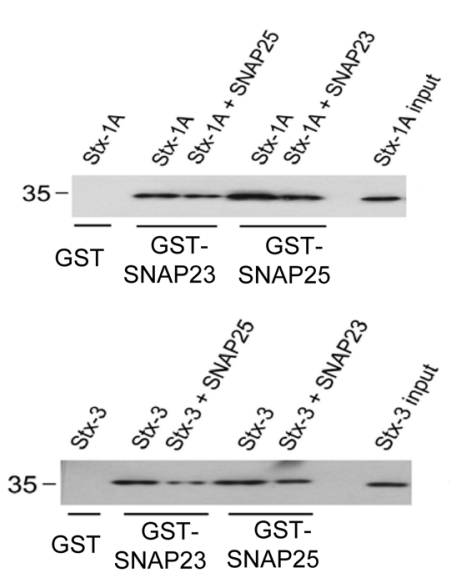

Glucose(mM) $\quad 0.8 \quad 16.7$

GLP-1(10nM) $\frac{0 \quad 10}{\text { SNAP23 Input }}$
B
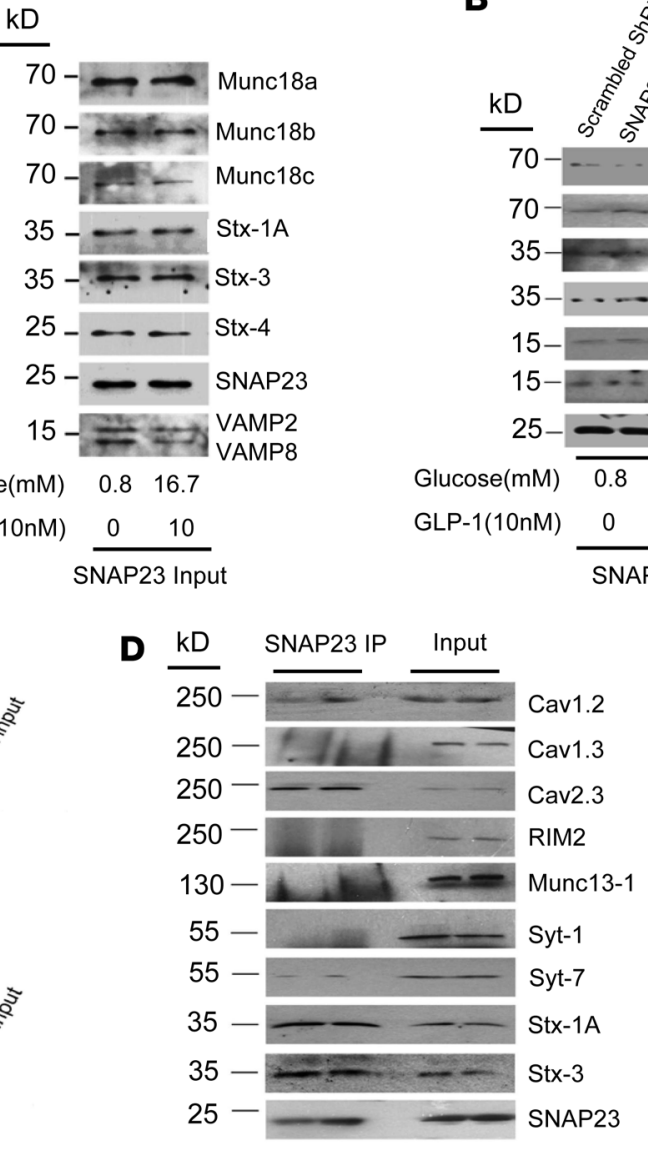

Glucose $(\mathrm{mM}) \quad 0.816 .7 \quad 0.8 \quad 16.7$

$\begin{array}{lllll}\text { GLP-1(10nM) } & 0 & 10 & 0 & 10\end{array}$
F

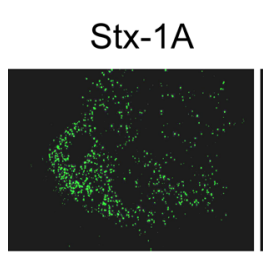

box 1
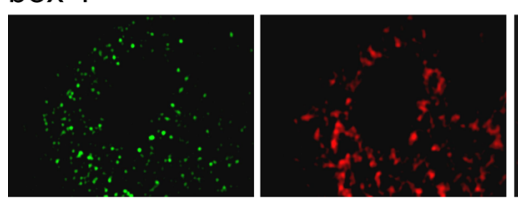

Control
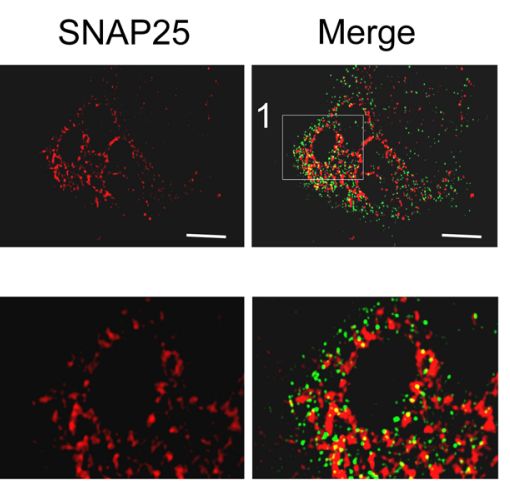

Stx-3

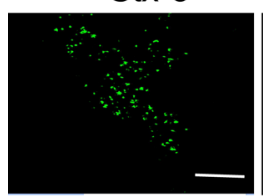

SNAP25

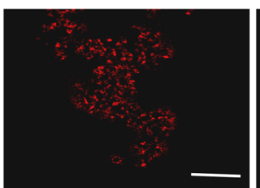

box 3
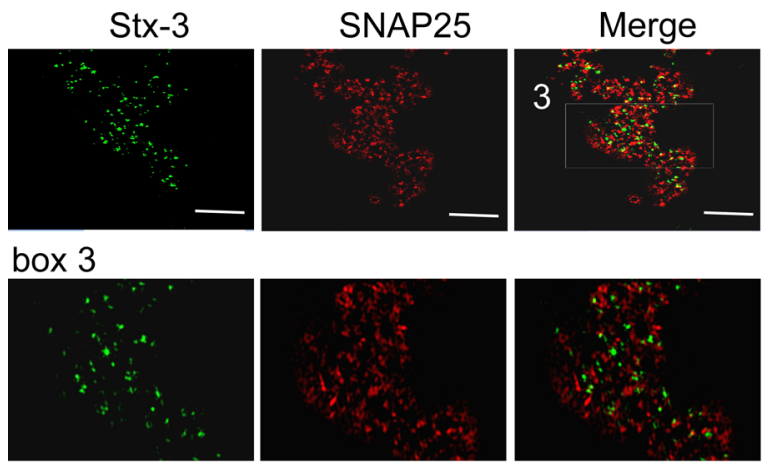

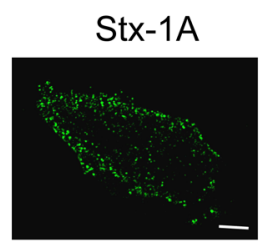

box 2

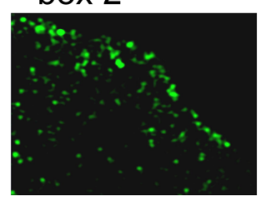

Stx-3

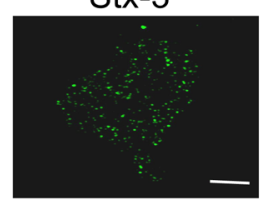

box 4

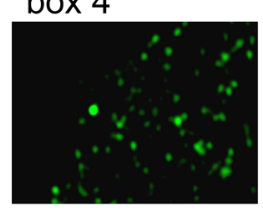

SNAP23 KD

E $\mathrm{kD}$ SNAP25IP Input

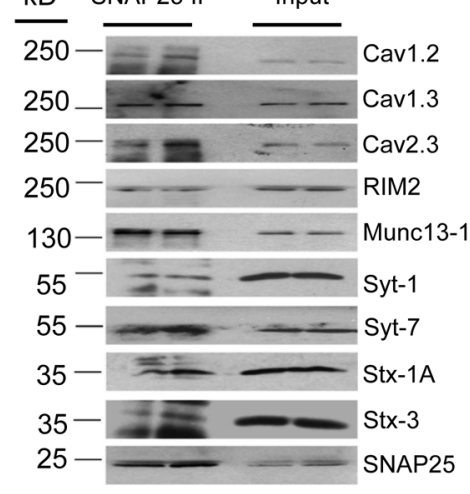

Glucose(mM) $0.816 .7 \quad 0.8 \quad 16.7$

GLP-1(10nM) $\quad 0 \quad 10 \quad 0 \quad 10$
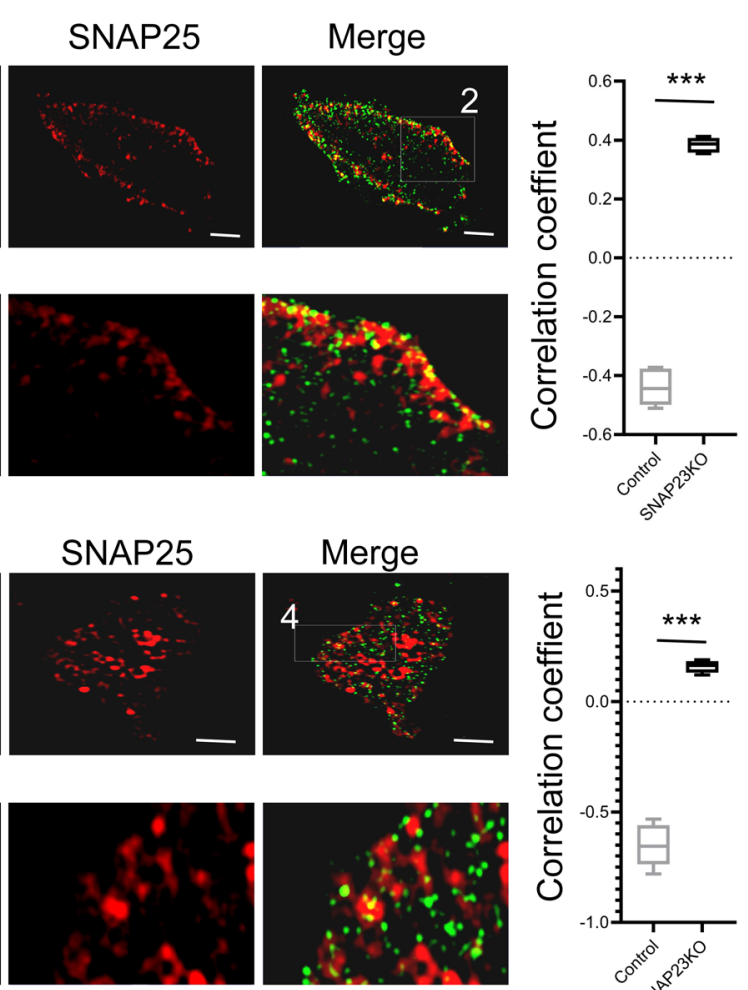

Merge
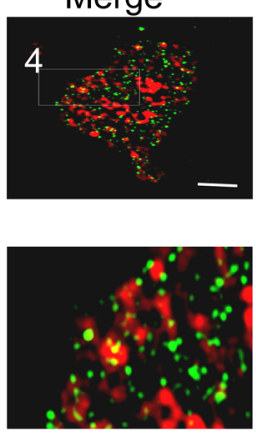
Figure 8. SNAP23 acts as inhibitory SNARE that reduces SNAP25 binding to Stx-1A and Stx-3 from forming SNARE complexes, whereby these SNAP25 but not SNAP23 SNARE complexes could form more fusion-competent machineries with $\mathrm{Ca}_{\mathrm{v}}$, priming proteins and $\mathrm{Ca}^{2+}$ sensors. Coimmunoprecipitation (Co-IP) studies were performed on INS-832/13 cells before stimulation (basal) and after maximal stimulation with $16.7 \mathrm{mM}$ glucose plus $10 \mathrm{nM}$ GLP-1. (A) SNAP23 forms similar SM/SNARE complexes as those previously reported with SNAP25. Co-IP was performed with SNAP23 antibody. Shown are representative of 3 experiments with analysis of the 3 experiments shown in Supplemental Figure 7A. (B) SNAP23 depletion in INS-832/13 cells enables endogenous SNAP25 to promote formation of more SM/SNARE complexes to mediate the increased exocytosis of predocked SGs (Munc18a, Stx-1A, VAMP2) and newcomer SGs (Munc18b, Stx-3, VAMP8) that underlie the increased first- and second-phase GSIS shown in Supplemental Figures 2-4. INS-832/13 cells were first treated with Ad-SNAP23 shRNA/mCherry to deplete SNAP23 versus Ad-scrambled shRNA/mCherry (Control). Co-IP was performed with SNAP25 antibody. Shown are representative of 3 experiments, with analysis of the 3 experiments shown in Supplemental Figure 7B. (C) SNAP23 blocks SNAP25 (and vice versa) binding to Stx-1A and Stx-3. HEK293 cells transfected with Stx-1A, Stx-3, SNAP23, or SNAP25 were subjected to pulldown with GST-SNAP23 (in the presence or absence of expressed SNAP25) or GST-SNAP25 (in the presence or absence of expressed SNAP23) to assess how much Stx-1A (top) or Stx-3 (bottom) could be precipitated. CST was used as control. Shown are representative of 4 experiments, with analysis of the 4 experiments shown in Supplemental Figure 7C. SNAP23 SNARE complexes (D) are less able than SNAP25 complexes (E) to pull down Ca $\mathrm{s}$ (Ca $1.2,-1.3$, and -2.3) synaptotagmins (Syt-1 and -7) and priming proteins (RIM2, Munc13-1). Note that $16.7 \mathrm{mM}$ glucose plus GLP-1 increased the binding of some of these proteins in SNAP25 but not SNAP23 complexes. This is a representative of 3 separate experiments with analysis shown in Supplemental Figure 8. (F) Control (Ad-scrambled shRNA/mCherry) or SNAP23-knockdown (Ad-SNAP23 shRNA/mCherry) human $\beta$ cells were stimulated with 16.7 mM glucose plus 10 nM GLP-1, immunolabeled with SNAP25 and Stx-1A or Stx-3 antibodies, and then assessed by structured illumination microscopy imaging. SNAP23 depletion increased SNAP25 colocalization with Stx-1A (top; Pearson's correlation coefficient [PCC], Control: $-0.42 \pm 0.09 ; \mathrm{KD}: 0.36 \pm 0.04, n=11$ from 2 independent experiments) and Stx-3 (bottom; PCC, Control: $-0.74 \pm 0.06$ : KD: $0.14 \pm 0.02, n=12$ from 2 independent experiments). Scale bars: $2 \mu \mathrm{m}$. ${ }^{* * *} P$ $<0.001$. Statistical significance was assessed by 2-tailed Student's $t$ test.

We assessed this by expressing Stx-1A and/or Stx-3 in HEK293 cells and measured how much of these syntaxins were pulled down by GST-SNAP23 ( \pm SNAP25) or GST-SNAP25 ( \pm SNAP23) (Figure 8 C). SNAP23 reduced GST-SNAP25 binding to Stx-1A by 39\% and to Stx-3 by 52\% (analysis in Supplemental Figure 7C). However, SNAP25 also reduced to a similar extent (analysis in Supplemental Figure 7C) GST-SNAP23 binding to Stx-1A (by 48\%) and Stx-3 (by 65\%). To translate these binding studies performed in cell lines into bona fide spatiotemporal functional interaction studies in human $\beta$ cells, Figure $8 \mathrm{~F}$ shows that after knockdown of SNAP23 expression with Ad-SNAP23-shRNA/mCherry (48 hours treatment, cytosolic mCherry signal was used to identify the infected $\beta$ cells), high-resolution single-molecule imaging by structured illumination microscopy showed that stimulation (16.7 mM glucose $+10 \mathrm{nM}$ GLP-1 for 10 minutes) increased the colocalization of endogenous SNAP25 (labeled with Alexa Fluor 647) on the PM with the endogenous Stx-1A (Pearson's correlation coefficient increased from $-0.42 \pm 0.09$ to $0.36 \pm 0.04$ ) and Stx-3 (Pearson's correlation coefficient increased from $-0.74 \pm 0.06$ to $0.14 \pm 0.02$ ) compared with control.

These results support our thinking that in the context of the $\beta$ cell, SNAP23 is a weaker (partial agonist) fusion SNARE or possibly an inhibitory SNARE $(22,37)$, the latter becoming manifest when SNAP25 levels are low, as in T2D islets (31-34). Taken together with the BSNAP23-KO TIRF microscopy study (Figure 3C), our results suggest that SNAP23-driven SNARE complexes may be less fusion competent than SNAP25-driven complexes. We then assessed why this might be the case. The fusion machinery involves not only SNARE complexes but also very complex interactions with $\mathrm{Ca}_{\mathrm{v}} \mathrm{s}$ to form excitosomes (23) that position SGs to fuse at PM sites of maximal $\mathrm{Ca}^{2+}$ influx, and additional priming proteins (RIM2, refs. 38, 39; Munc13-1, refs. 40, 41) and $\mathrm{Ca}^{2+}$ sensors (synaptotagmins 1 and 7 (Syt-1 and -7) $(42,43)$ known to optimize fusion competence $(1,2)$. We performed a more exhaustive analysis of SNAP23 (Figure 8D and Supplemental Figure 8A) and SNAP25 coprecipitated proteins (Figure 8E and Supplemental Figure 8B). Both SNAP25 and SNAP23 coprecipitated $\mathrm{Ca}_{\mathrm{v}} 1.2$ and $\mathrm{Ca}_{\mathrm{v}}$ 2.3. SNAP25, not SNAP23, precipitated RIM2 and Munc13-1. SNAP23 precipitated small amounts of Syt-1, whereas SNAP25 pulled down abundant Syt-1 and Syt-7. Importantly, physiologic glucose plus GLP-1 stimulation increased SNAP25 (but not SNAP23) pulldown of $\mathrm{Ca}_{\mathrm{v}} 1.2, \mathrm{Ca}_{\mathrm{v}} 2.3$, Syt-1, and Syt-7.

SNAP23 depletion promotes more SNAP25 to move more rapidly and stay longer on $\mathrm{Ca}_{v}$ to increase exocytotic efficiency. The biochemical data in Figure 8 are insufficient to prove but nevertheless suggest why SNAP25 machinery might be more fusion competent than the SNAP23 machinery. We thus proceeded to functionally demonstrate the nature of this improved fusion competence caused by SNAP23-KO (Figure 9A) compared with SNAP25 overexpression (Figure 9B). We employed high-resolution dual-color single-molecule imaging (see Methods) to visualize the spatiotemporal interactions between individual SNAP25 molecules and $\mathrm{Ca}_{\mathrm{v}} \mathrm{s}$ (the prototypical L-type $\mathrm{Ca}_{\mathrm{v}} 1.2$; refs. 27,41 ) at the PM surface of live INS-832/13 cells. SNAP25 tagged with $\mathrm{mScarlet}$ was transiently expressed at low densities in $\mathrm{Ca}_{\mathrm{v}} 1.2$-mNeonGreen-knockin INS-832/13 cells (see Supplemental Figure 9B). SNAP25 molecules showed 2 distinct behaviors, either high motility or relative immobility, the latter resulting from taking residence on a $\mathrm{Ca}_{\mathrm{v}} 1.2$ (Figure 9, $\mathrm{A}$ and B). We estimated the frequency and duration of SNAP25-Ca 1.2 interactions, whereby within 5 seconds after $8 \mathrm{mM}$ glucose stimulation (Figure 9C), the average cumulative interaction time between SNAP25 and $\mathrm{Ca}_{\mathrm{v}} 1.2$ in SNAP23-KO 
A
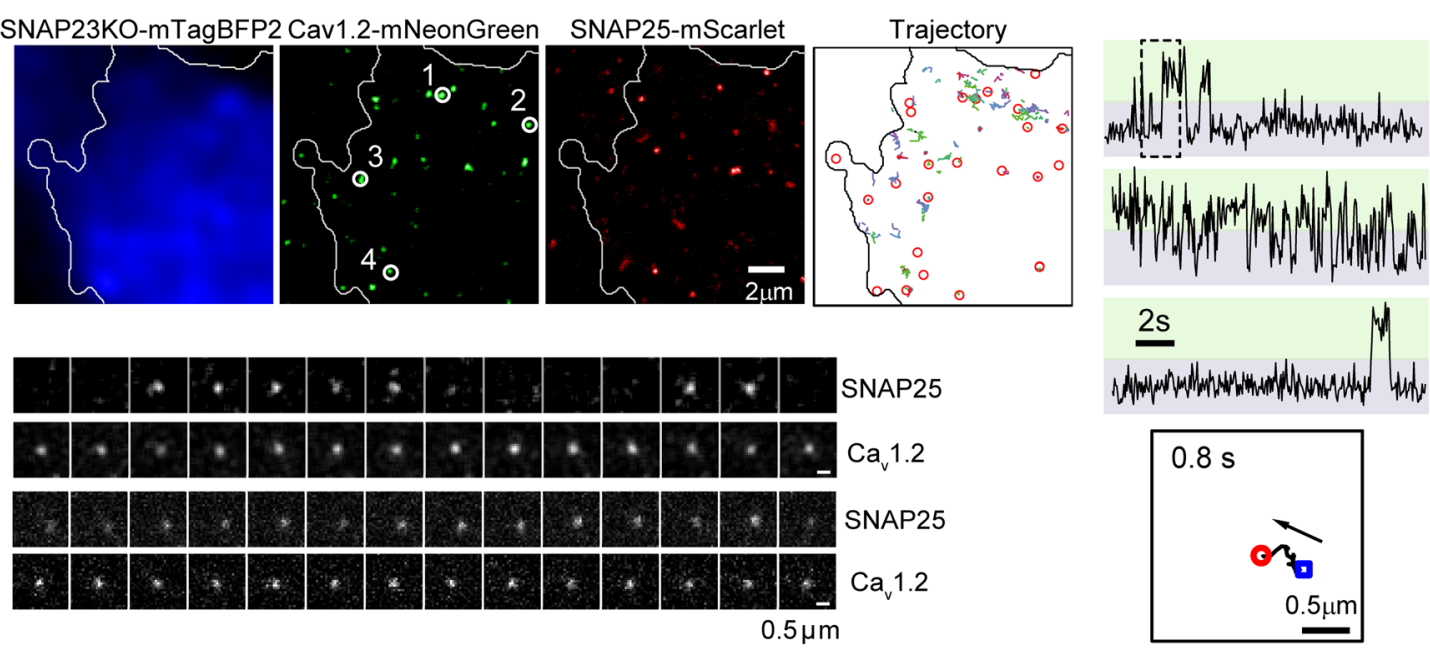

B
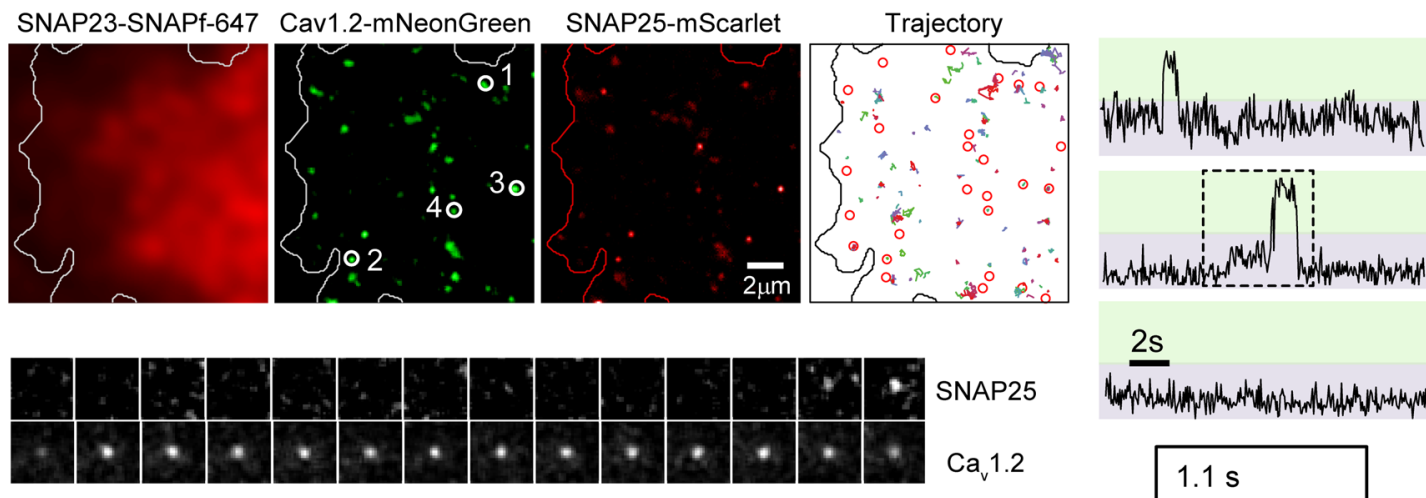

SNAP25

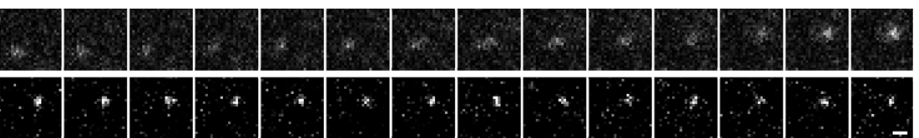

$\mathrm{Ca}_{\mathrm{v}} 1.2$

SNAP25

$\mathrm{Ca}_{\mathrm{v}} 1.2$
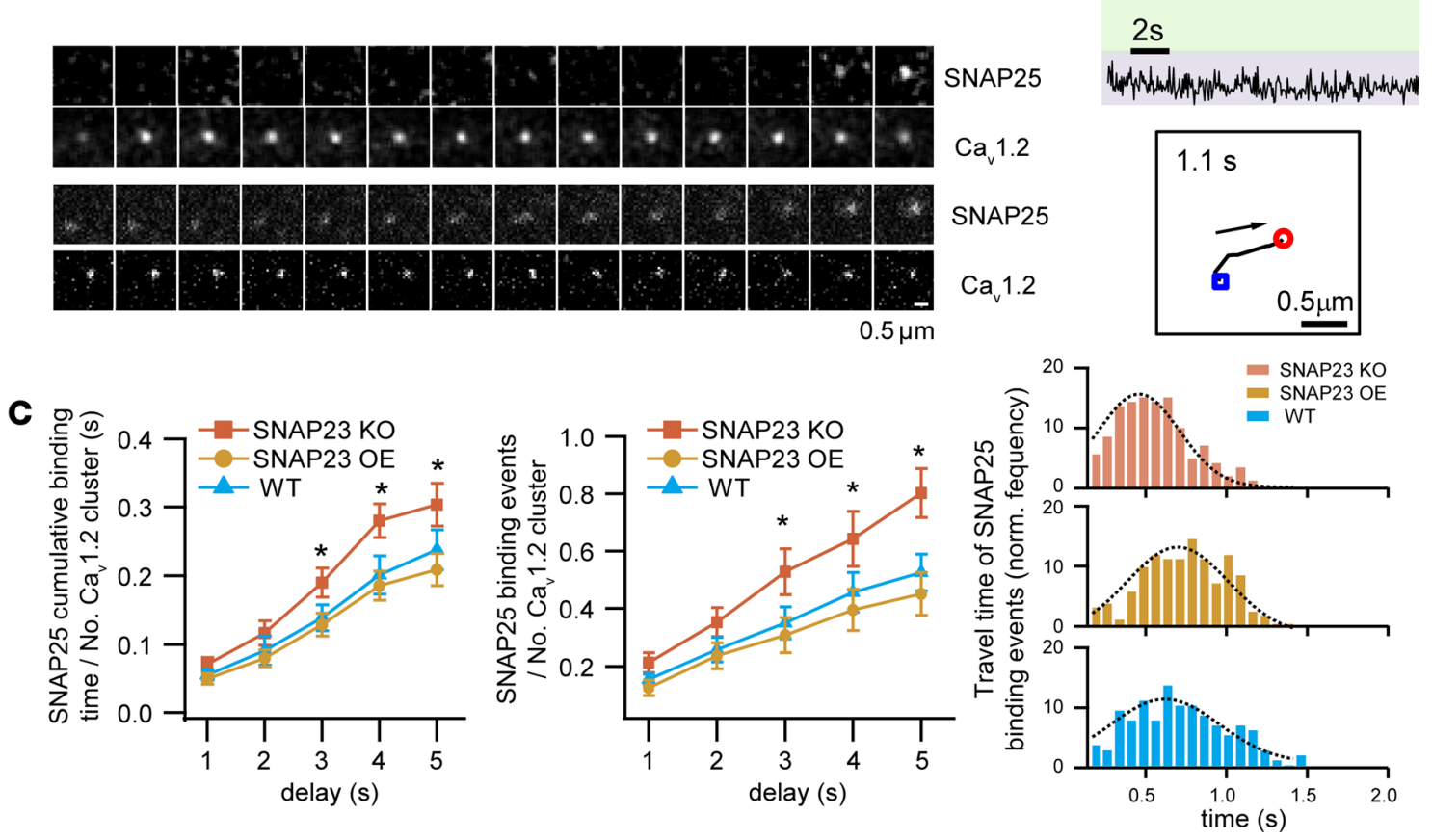

Figure 9. Live-cell single-molecule localization and tracking of SNAP25-mScarlet binding to endogenous Ca 1 1.2. (A) SNAP23-knockout (SNAP23-KO) INS-832/13 cells. (B) SNAP23-overexpressing (OE) INS-832/13 cells. Representative live-cell single-molecule image of SNAP25-mScarlet and Ca -mNeonGreen in SNAP23-KO (A, top left) and SNAP23-OE (B, top left) INS-832/13 cells; these images are representative of 4 independent experiments. (A, top left) Endogenous $\mathrm{Ca}_{\mathrm{v}} \mathrm{1} .2$ in SNAP23-KO cells (mTagBFP2) was labeled with mNeonGreen by an MMEJ-mediated knockin method as previously described (54) and shown in detail in Supplemental Figure 9 and described briefly in the Methods. Right: The trajectories of SNAP25-mScarlet were overlaid onto the locations of the endogenous $\mathrm{Ca}_{\mathrm{v}} 1.2$ clusters (indicated in red circles). (A, top right) Representative intensity traces of single SNAP25-mScarlet molecules binding to $\mathrm{Ca}_{1} 1.2$ clusters (from top to bottom, white circles 1-3 indicated in $\mathbf{A}$, top left). (A, bottom left) Examples of sequential images of the mobility of single SNAP25-mScarlet coming from the cytoplasm (top: corresponds to white circle indicated as event 4 in $\mathbf{A}$, top left) or along the PM (bottom: corresponds to white circle indicated as event 1 in $\mathbf{A}$, top left) traveling to bind a $\mathrm{Ca}_{\mathrm{v}} 1.2$ cluster; the latter trajectory shown in (A, bottom right). Blue rectangle indicates the start, red circle indicates the location of $\mathrm{Ca}_{v}$ 1.2. (B, top left) $\mathrm{Ca}_{v} 1.2-\mathrm{knockin}$ INS-832/13 cells were transfected with SNAP23-SNAPf for 24 hours and then incubated with far-red fluorescent substrate, 647-SiR, for imaging. SNAP25-mScarlet was transfected again for 3 to 6 hours before imaging. Trajectories of SNAP25-mScarlet were overlaid onto the locations of endogenous $\mathrm{Ca}_{\mathrm{v}}$ (indicated as red circles). (B, top right) Representative intensity traces (from top to bottom, white circles 1-3 indicated in B, top left). (B, bottom left) Two examples of sequential images showing the mobility of single 
SNAP25-mScarlet molecules coming from the cytoplasm (top: corresponds to white circle indicated as event 2 in B, top left) or along the PM (bottom: corresponds to white circle indicated as event 4 in B, top left) traveling to bind Ca 1.2 clusters; the latter trajectory shown in $\mathbf{B}$, bottom right. (C) Comparison between SNAP23-KO versus WT versus SNAP23-OE. Left: Cumulative dwell time of SNAP25 binding to Ca 1.2 per Ca 1.2 clusters. Middle: Cumulative frequency of SNAP25 binding to $\mathrm{Ca}_{\mathrm{v}} 1.2$ per Ca 1.2 clusters. Right: Travel time histogram of single events of SNAP25 binding to Ca 1.2 ( $n=10$ each from 4 independent experiments). ${ }^{*} P<0.05$. Statistical significance was assessed by repeated-measures ANOVA.

was $41 \%$ longer than SNAP23-overexpressing cells (left, KO: $0.31 \pm 0.03$ seconds, overexpressing: $0.22 \pm$ 0.02 seconds) and SNAP25 binds to $\mathrm{Ca}_{\mathrm{v}} 1.2$ with an $88 \%$ increase in the frequency (middle, $\mathrm{KO}: 0.79 \pm 0.09$, overexpressing: $0.42 \pm 0.08$ ), indicating a higher binding affinity of SNAP25 for $\mathrm{Ca}_{\mathrm{v}} 1.2$. in SNAP23-KO than SNAP23-overexpressing cells. Correspondingly, SNAP25 travel time to $\mathrm{Ca}_{\mathrm{v}} 1.2$ was much shorter in SNAP23KO cells (Figure 9C, right; also compare the trajectories in Figure 9A, bottom right, and Figure 9B, bottom right). Control cells using a blank vector to infect WT INS832/13 cells showed similar (very slightly but insignificantly better) frequency, travel time, and duration of SNAP25-Ca 1.2 interactions as SNAP23-overexpressing cells (Figure 9C).

This increased SNAP25-Ca 1.2 binding affinity caused by SNAP23 depletion would be expected to improve fusion competence, which was tested in Figure 10, assessing the spatial relationship between insulin SG fusions (NPY-tdmOrange2; ref. 44) and $\mathrm{Ca}_{\mathrm{v}}$ 1.2. Compared with Control, SNAP23-KO results in increased average SG exocytosis on $\mathrm{Ca}_{\mathrm{v}} 1.2$ over time (Figure 10E), with estimated probability of $\mathrm{Ca}_{\mathrm{v}} 1.2$-localized SG fusion per channel cluster in SNAP23-KO cells to be 41\% higher (Figure 10E, SNAP23-KO: 0.24 \pm 0.02/min, Control: $0.17 \pm 0.02 / \mathrm{min}$ ). These quantitative results indicate that SNAP23 depletion increases the amount, speed, and duration of SNAP25 residence on $\mathrm{Ca}_{\mathrm{v}} 1.2$, which enhanced SG exocytotic efficiency at the $\mathrm{Ca}_{\mathrm{v}} \mathrm{s}$.

\section{Discussion}

SNAP23 forms the same SNARE complexes as SNAP25, and is thus expected to mediate exocytosis in $\beta$ cells as in slower secretory cells like acini (14) and adipocytes (13) that contain only SNAP23. In vitro fusion assays have confirmed that SNAP23 can mediate membrane fusion $(19,20)$. Our work showing that $\beta$ cell SNAP23 depletion paradoxically increased biphasic GSIS by increasing fusion of predocked and newcomer SGs in more secretory-efficient pancreatic $\beta$ cells indicates that the abundant endogenous SNAP25 could be relieved to exert its actions in mediating more efficient SG fusion at the $\mathrm{Ca}_{\mathrm{v}}$ than that mediated by SNAP23 (Figure 10). The reason for this is that SNAP23-KO enables not only more SNAP25 molecules to occupy $\mathrm{Ca}_{\mathrm{v}} 1.2$ clusters (Figure 9) as well as bind Stx-1A and Stx-3 (Figure 8F) to form excitosomes, but SNAP25 moved faster and stayed on longer on $\mathrm{Ca}_{\mathrm{v}} 1.2$ (Figure 9). Peculiarly, this enhanced residency of SNAP25 on $\mathrm{Ca}_{\mathrm{v}}$ did not alter channel activity or $\mathrm{Ca}^{2+}$ sensitivity of fusion.

In the most efficient secretors, neurons, SNAP25 is the only putative cognate SNARE partner of Stx$1 \mathrm{~A}$ and VAMP2 in mediating synaptic vesicle release from presynaptic nerve terminals $(1,21)$, although SNAP23 has been found in dendritic spines (45). Nonetheless, SNAP23, exogenously expressed in SNAP25-deleted chromaffin cells, could not support primed SGs that were well supported by SNAP25 (21). SNAP23 exogenously expressed in SNAP25-deleted neurons (neurons do not contain SNAP23) could only support asynchronous release (46), and was shown to require the $\mathrm{Ca}^{2+}$ sensor Syt-7 (47). Interestingly, Syt-7 is the major $\mathrm{Ca}^{2+}$ sensor for insulin SG exocytosis in $\beta$ cells $(42,43)$. In contrast, Syt-1, the major $\mathrm{Ca}^{2+}$ sensor in neurons for synchronous release (48), could effect efficient fusion with the Stx-1A/SNAP25 complex in in vitro fusion assays, but when replaced with SNAP23, fusion became less efficient (20). In fact, Syt-1 had little effect on VAMP2-to-SNAP23 vesicle fusion (20). Taken together, these results show that SNAP23 is a less efficient fusion protein than SNAP25, which serves its purpose in slower secretory cells like acini (14), muscles, and adipocytes $(4,13)$. However, when both SNAP23 and SNAP25 are abundantly present, our data in Figure 3, B and C, suggest that the less fusion-competent SNAP23 competes with fusion-competent SNAP25 to reduce SNAP25 efficiency in forming exocytotic complexes.

Our results differ from a just-published study by Kunii et al. using a genetically deleted $\beta$ cell SNAP23KO mouse (49), in contrast with our AAV8-RIP1-Cre virus 2-week-induced knockdown of SNAP23 in SNAP2 $3^{\mathrm{f} / \mathrm{fl}}$ mice, which showed unequivocal knockdown of only $\beta$ cell SNAP23. The study by Kunii et al. showed that SNAP23 deletion only increased predocked SG fusion along with a corresponding increase in predocked SG SNARE complexes underlying an increased first-phase GSIS (49). Our study showed that SNAP23 deletion also increased newcomer SG fusions by increasing newcomer SG SNARE complexes, which also increased second-phase GSIS. Hence, SNAP23 deletion in $\beta$ cells resulted in potentiation of 
A

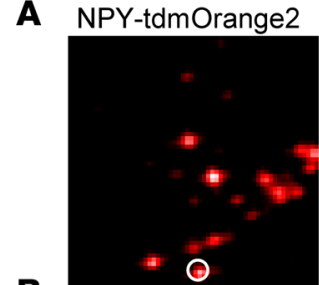

B

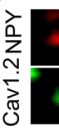

$+0$
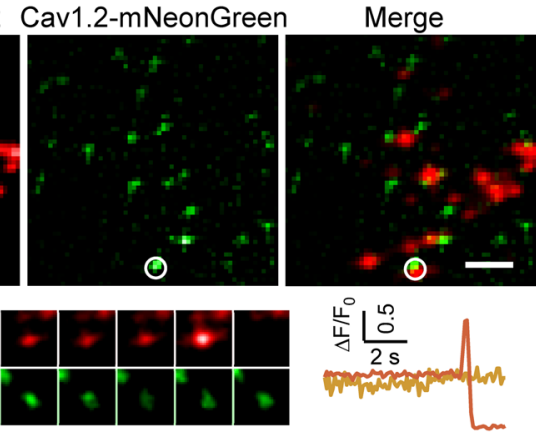

C

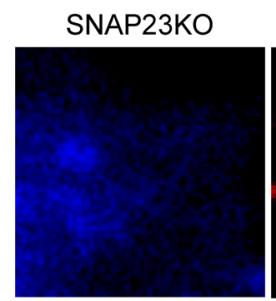

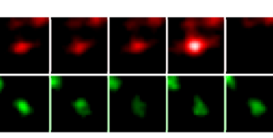

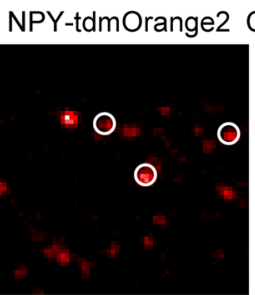

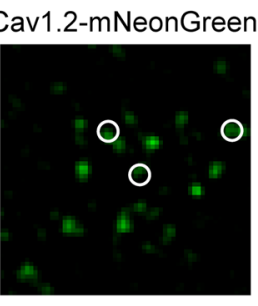

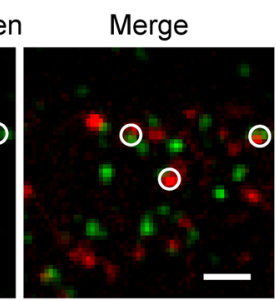

D
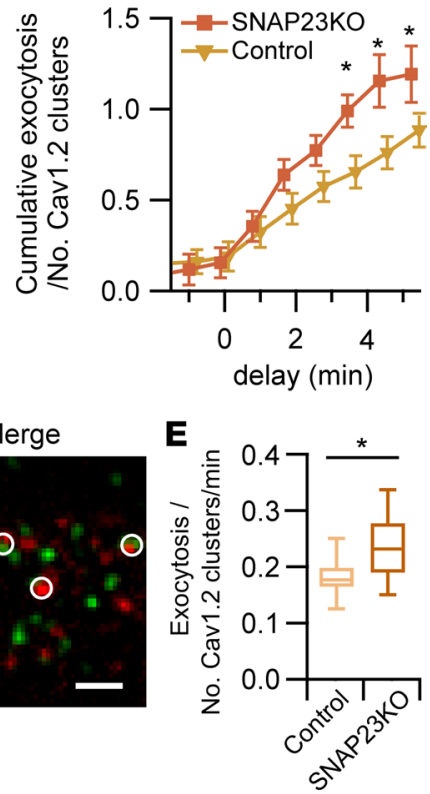

Figure 10. Individual insulin SC exocytosis at Ca 1.2 clusters. (A) Control INS-832/13 cells. (C) SNAP23-knockout cells. Data are representative of 3 independent experiments. Scale bars: $2 \mu \mathrm{m}$. (B) Representative montage of SC exocytosis at $\mathrm{Ca}_{\mathrm{v}} 1.2$ clusters. (D) Cumulative exocytosis events per $\mathrm{Ca}_{\mathrm{v}} 1.2$ cluster along the different time points during stimulation. (E) Average exocytosis events per $\mathrm{Ca}_{\mathrm{v}} 1.2$ cluster per minute (12 cells each from 3 independent experiments). ${ }^{*} P<0.05$. Statistical significance was assessed by 2-tailed Student's $t$ test.

biphasic GSIS not only in normal mouse (Figure 2; also shown in the Kunii et al. study) and human islets (Figure 4), but our work further showed near-normalization of the deficient GSIS in T2D human islets (Figure 5) and GK rat islets in vivo with a single treatment of a SNAP23 shRNA-containing virus, achieving a sustained effect of a long duration of 4 months that exceeded conventional glybenclamide treatment (Figure 7). In the latter, the improved glucose homeostasis was sustained for 3 hours after glucose load, encompassing the effects of improved biphasic GSIS. This is different from the merely first-phase (but not second-phase) GSIS improvement in the Kunii et al. study. The latter indicates a genuine therapeutic potential for T2D compared with just amplifying first-phase GSIS in the Kunii et al. study, and implies that even the very low abundance of residual SNAP25 (Figure 5A), when not competed with by SNAP23, could bind low levels of the cognate SNAREs Stx-1A and VAMP2 in T2D islets (refs. 31, 33, 34; Figure 5A) to still mount sufficient exocytotic machinery to effect near-normal GSIS. Another possibility to explain the improved GSIS in SNAP23-depleted T2D islets is that normal islet levels of Stx-3 (8) and Stx-4 (50) (Figure $5 \mathrm{~A})$ could compensate for Stx-1A deficiency.

Our work thus suggests that SNAP23 acts as a weak partial fusion agonist in some secretory cells, but in the context of $\beta$ cells, SNAP23 effectively acts as an antagonist to SNAP25-mediated fusion. Our single-molecule imaging study showed that SNAP23 depletion increased SNAP25 localization to Stx-1A and Stx-3 (Figure $8 \mathrm{~F}$ ) to form SNARE complexes (Figure 8, A-C). We further provide a biochemical basis for the superior fusion competence of SNAP25 compared with SNAP23. Figure 8, D and E, shows that SNAP25 and/or its SNARE complex have greater capacity to bind $\mathrm{Ca}_{v} \mathrm{~s}$ to form excitosomes to position $\mathrm{SGs}$ to $\mathrm{Ca}_{\mathrm{v}} \mathrm{s}$ where fusion occurs (23), which we confirmed in Figure 10. Importantly, SNAP25 or its SNARE complex has even greater capacity to bind major priming proteins (RIM2, Munc13-1) and $\mathrm{Ca}^{2+}$ sensors (Syt-1, Syt-7), for which SNAP23 or its SNARE complex has low to no affinity. This is likely a basis of the superior fusion competence of SNAP25 over SNAP23. While there are limitations to interpreting coimmunoprecipitation studies to indicate mechanistic interactions, which require complex direct molecular interactions studies, we have shown some single-molecule imaging data for SNAP25-Stx-1A/Stx-3 (Figure 8F) and SNAP25$\mathrm{Ca}_{\mathrm{v}}$ interactions (Figure 9); these biochemical studies are likely physiological because glucose stimulation increased binding to some of these proteins including Syt-7 and $\mathrm{Ca}_{v}$ s, along with cognate Munc18 and SNARE proteins. These precise mechanistic insights were not elucidated in the Kunii et al. study (49). 
Teleologically, SNAP23 can act as a cell context-specific inhibitory SNARE (21) when it coexists with SNAP25 to better fine-tune membrane fusion. In $\beta$ cells, SNAP23 works on slow insulin release and SNAP25 acts on fast insulin release. This slow insulin release may regulate the fast insulin release mechanism in a cell-autonomous manner. Removal of the slow release mechanism by SNAP23-KD removes this autoregulatory mechanism. Peculiarly, in T2D human islets, SNAP23 levels are not reduced, whereas there is a severe reduction in SNAP25 levels (discussed above). This suggests that SNAP23 would exert a stronger antagonism against the residual SNAP25 in T2D $\beta$ cells than when SNAP25 levels are abundant in normal islets. Alternatively, insulin SG exocytosis in T2D human $\beta$ cells employing SNAP23 would be less efficient because of slower fusion kinetics mediated by SNAP23, which might partly explain why there is still substantial, albeit reduced, possible SNAP23-mediated second-phase GSIS from T2D islets. This would suggest a shift from regulated fast SNAP25-mediated insulin release in normal islets to slow SNAP23-mediated insulin release in T2D islets. It is possible that the less regulated SNAP23-mediated release contributes to the higher basal insulin release observed in T2D.

This concept of an inhibitory SNARE (22) has never been demonstrated to our knowledge in vivo in a manner affecting whole-body homeostasis until our recent and current work. While rapid, short-burst patterns of exocytosis are characteristic of neurons, a slower and more prolonged secretory pattern of minutes to several hours is the norm for $\beta$ cells and other endocrine cells. These dual SNAP25 isoforms provide a push-pull mechanism (with the push mediated by SNAP25 and pull by SNAP23) designed to deliberately reduce the efficiency of insulin exocytosis for the purpose of conferring a sustained, metered release. Because SNAP23 forms the same SNARE complexes as SNAP25, the reduced pull from SNAP23 depletion enabled SNAP25 to form more fusion-competent SNARE complexes (with priming proteins and $\mathrm{Ca}^{2+}$ sensors), thus providing more push to mediate exocytosis of predocked SGs (with Stx-1A and VAMP2) and newcomer SGs (with Stx-3 and VAMP8) $(2,6,8)$ that underlie first- and second-phase GSIS, respectively. This would explain why SNAP23 depletion in normal and T2D human islets increased biphasic GSIS. Stx-2 likely also acts as an inhibitory SNARE to compete with Stx-1A and Stx-3 (37), which would explain why $\beta$ cell Stx-2 deletion promoted exocytosis of Stx-1A-mediated predocked and Stx-3-mediated newcomer SGs. Teleologically, the presence of inhibitory SNAREs serves to modulate different exocytotic efficiency between secretory cell types, such as fast-secreting neurons (predominantly SNAP25) versus moderately-fast-secreting endocrine cells (both SNAP25 and SNAP23) versus slow-secreting acinar cells and adipocytes (predominantly SNAP23).

Our results present intriguing possibilities for potential therapies for diabetes such as reducing pancreatic islet SNAP23 levels with an shRNA-containing virus in T2D patients in vivo by endoscopic perfusion of the virus, which should mimic this study with GK rat pancreatic ductal perfusion (Figure 7), wherein a single shot lasted a remarkable 4 months. Alternatively, isolated human islets could be treated with the shRNA-containing virus in vitro for use in transplantation in type-1 diabetes patients. The latter could allow a smaller number of surviving enhanced-secreting $\beta$ cells with enough insulin secretory capacity to achieve glucose homeostasis, as suggested in Figure 4. Adenovirus, the effects of which begin to wane after just 2 months (this study), is of course not the ideal gene transfer strategy; a longer-acting, single-shot, safer gene transfer approach recently shown with an AAV carrying a $\beta$ cell promoter (26) will be required to proceed to human trials (51). This also raises the possibility of employing strategies for specific manipulation of SNAP23 or SNAP25 levels in other secretory cells to treat the corresponding diseases of oversecretion (then overexpress SNAP23 to slow down secretion) or undersecretion (then overexpress SNAP25 to accelerate secretion). Alternatively, a small compound like MF286, as reported in the Kunii et al. study, which binds specifically to SNAP23 to block SNARE complex assembly, was shown to promote GSIS in mice (49). Caution should, however, be taken in these approaches, as distinct functions of SNAP23 and SNAP25 are likely dependent on other cognate exocytotic proteins shown in Figure 8, D and E, and others yet undefined, which may further alter SNAP23 or SNAP25 actions in a cell context-specific manner.

\section{Methods}

\section{Antibodies and reagents}

SNAP23 (catalog 111203), Stx-2 (catalog 110123), Stx-3 (catalog 110033), Stx-4 (catalog 110043), and tubulin (catalog 302008) antibodies were procured from Synaptic Systems; Stx-1A (catalog SAB5600255), insulin (catalog SAB4200691), and glucagon (catalog SAB4200685) antibodies were from Sigma-Aldrich; SNAP25 antibody was from Sternberg Monoclonal (Covance); Munc18a antibody (catalog 610336) was from BD 
Transduction Laboratories; and Cre antibody (catalog PRB-106P) was from Covance. As gifts, Munc18b was from V. Olkkonen (Minerva Foundation Institute, Biomedicum, Helsinki, Finland), Munc18c antibody was from D. Thurmond (City of Hope, Duarte, California, USA), VAMP2 antibody was from A. Lowe (Stanford University, Stanford, California, USA), and VAMP8 antibody from W. Hong (Institute of Molecular and Cell Biology, Singapore). Alexa Fluor 488 (catalog A11008), Alexa Fluor 647 (catalog A32728), Alexa Fluor 647 phalloidin (catalog A22287), GM 130 antibody (Golgi marker) (catalog PA1-077), FITC (catalog 711900), and Texas Red (catalog A6399) were from Thermo Fisher Scientific. All other chemicals, unless specified, were obtained from Sigma-Aldrich. Ad-SNAP23-human shRNA-mCherry (shRNA sequence: CCGGGAGTCTGGCAAGGCTTATAAGCTCGAGCTT ATAAGCCTTGCCAGACTCTTTTTG and Ad-SNAP23-mouse/ rat shRNA-mCherry (shRNA sequence: CCGGGAACAACTAAATCGCATAGAACTCGAGTTCTATGCGATTTAGTTGTTCTTTTTG were purchased from Vector Biolabs.

Generation of SNAP23 $3^{\mathrm{f} / \mathrm{fl}}$ mice and $\beta$ cell-specific SNAP23-deleted mouse SNAP23 $3^{\mathrm{f} / \mathrm{fl}}$ mice were generated by Ozgene, as we have recently reported (24). Briefly, a targeting construct was generated that contained 5.9 and $4.6 \mathrm{~kb}$ upstream of exon 2 and downstream of exon 4, respectively. LoxP sites were inserted, flanking exons 3 and 4, and the neo selection cassette was flanked by FRT sites. Following homologous recombination, ES implantation and generation of SNAP2 $3^{\mathrm{fl} / \mathrm{fl}}$ mice in the C57BL/6J background, the neo cassette was removed by crossing with FLP-recombinase mice. This mouse strain has been continually maintained in the C57BL/6J background for over 10 generations. Instead of crossing the SNAP $23^{\mathrm{f} / \mathrm{ft}}$ mouse with a RIP1-Cre mouse to embryologically delete SNAP23 in $\beta$ cells, we employed the AAV8-RIPCre to delete $\beta$ cell SNAP23 in the adult mouse. The viral construct contains $410 \mathrm{bp}$ of rat INS1 promoter, including the first exon, first intron, and UTR of exon 2, followed by Cre recombinase ORF and an SV40 polyA signal. Recombinant dsAAV8 production to a titer of $1 \times 10^{13}$ plaque-forming units $(\mathrm{PFU}) / \mathrm{mL}$ was outsourced to The Center of Cellular and Molecular Therapeutics at the Children's Hospital of Philadelphia Research Vector Core (Philadelphia, Pennsylvania, USA). AAV8-RIP1-Cre at a dose of $1 \times 10^{12}$ PFU was injected into the peritoneum (i.p.) of 8- to 10-week-old SNAP2 $3^{\mathrm{fl} / \mathrm{fl}}$ male mice (C57BL/6J background). Two weeks after the i.p. injection, SNAP23 levels in the islet $\beta$ cells were greatly reduced (see Results) and remained so for several months, encompassing the in vivo experimental period performed on these mice and in vitro studies on the islets isolated from these mice performed as we have described $(6,17)$.

\section{Human islet and $\beta$ cell SNAP23 knockdown and overexpression}

Human islets were from institutional review board-approved healthy (10 donors) and diagnosed T2D donors (5 donors), as shown in Supplemental Table 1, with either written informed consent from the donor or the next of kin. Control (scrambled shRNA/mCherry), Ad-SNAP23 shRNA/mCherry (human and mouse), and Ad-SNAP23/mCherry and Control (Ad-mCherry) were from Vector Biolabs. Islets or dispersed $\beta$ cells were infected with Ad-SNAP23 shRNA/mCherry or Ad-SNAP23/mCherry for 48 hours to knock down or increase SNAP23 expression, respectively, with parallel infections with their respective control viruses. Entry of viral particles after transduction was determined by mCherry fluorescence expression.

\section{Confocal immunofluorescence microscopy}

This was performed as previously described $(6,8,17)$ using primary antibodies at 1:200 dilution and corresponding secondary antibodies. Immunostained cells mounted on glass coverslips were examined using a Leica DMIRE2 inverted fluorescence microscope containing a Hamamatsu spinning disk confocal scan head and back-thinned EM-CCD camera. Data acquisition and analysis were performed using Volocity software (PerkinElmer). A $20 \times$ objective lens was used for whole-islet imaging and $63 \times$ objective lens for single $\beta$ cell imaging. All images were deconvoluted by Volocity to remove background noise.

\section{Immunoprecipitation, in vitro binding, and Western blotting}

Immunoprecipitation. Similarly to previously described methods $(6,32)$, INS-832/13 cells (gift from C. Newgard, Duke University, Durham, North Carolina, USA) infected with Ad-SNAP23 shRNA/ mCherry or control virus, after 48 hours were then stimulated (or not) with $16.8 \mathrm{mM}$ glucose plus 10 nM GLP-1. Cell lysates, solubilized in immunoprecipitation (IP) buffer, were centrifuged $(55,000 \mathrm{~g}$, 40 minutes) to remove insoluble materials. The detergent pellet extract (600 $\mu$ g protein) was then precleared ( $35 \mu \mathrm{L}$ protein A agarose [50\% slurry], 1.5 hours) and incubated with protein A agarose-crosslinked anti-SNAP25 antibody $\left(2 \mu \mathrm{g}, 4^{\circ} \mathrm{C}, 1.5\right.$ hours $)$. 
In vitro binding. In vitro binding was performed as previously described (52). GST (as control), GSTSNAP23, or GST-SNAP25 (250 pmol protein) bound to glutathione-agarose beads was incubated with lysate extract (400 $\mu \mathrm{g}$ protein) of HEK293 cells transfected with Stx-1A, Stx-3, SNAP23, or SNAP25 in lysis buffer for 2 hours at $4^{\circ} \mathrm{C}$. The beads were then washed 3 times.

Western blotting. The precipitated proteins from IP and binding from the above were separated in $12 \%-$ $15 \%$ SDS-PAGE and identified with the indicated primary antibodies. Separately, whole pancreas, pancreatic islets, brain, fat, muscle, and liver were isolated from $\beta$ cell-specific SNAP23-KO and SNAP23 $3^{\mathrm{f} / \mathrm{fl}}$ Control mice. Normal and T2D human islets were treated with control or SNAP23-shRNA adenovirus. These lysate samples were separated in 12\%-15\% gradient SDS-PAGE, transferred to nitrocellulose membranes, and the separated proteins identified by the indicated primary antibodies. All blots were quantified by densitometry scanning followed by analysis with Scion Image (release beta 4.0.2).

\section{IPGTT, ITT, and glybenclamide treatment}

Before and 2 weeks after AAV8-RIP1-Cre injection to knock out the $\beta$ cell SNAP23 expression, the same mouse was subjected to these tests.

IPGTT. IPGTT (2 g glucose/kg BW) was performed after an 18-hour fast. The mice were gently restrained without anesthesia for blood collection from the tail vein for glucose determination by glucose strips and insulin determination by RIA (EMD Millipore). The GK rats underwent IPGTT ( $2 \mathrm{~g}$ glucose $/ \mathrm{kg}$ BW) before infusion and 1, 2, 4, and 8 weeks postoperatively following an 18-hour fast.

ITT. ITT was conducted by i.p. injection of human biosynthetic insulin (1 U/kg BW, Eli Lilly Canada Inc.) into mice or GK rats after a 6-hour fast; a drop of blood obtained from the tail vein at the indicated times was used for glucose determination.

Glybenclamide treatment. GK rats had free access to food and water. Glybenclamide was suspended in $0.5 \%$ methylcellulose and was delivered by oral gavage at the optimal dose of $2 \mathrm{mg} / \mathrm{kg}(36,53)$ and at a volume of $10 \mathrm{~mL} / \mathrm{kg}$ daily at $5 \mathrm{pm}$ for 8 weeks. Methylcellulose $(0.5 \%)$ was used as vehicle control, also at a volume of $10 \mathrm{~mL} / \mathrm{kg}(36,53)$. Insulin at a dose of $1 \mathrm{U} / \mathrm{kg} \mathrm{BW}$ was used for the ITT.

\section{Islet morphometry}

Pancreatic tissues from 4 SSNAP23-KO mice along with 4 littermate control SNAP23 ${ }^{\mathrm{f} / \mathrm{fl}}$ mice or GK rats were fixed for 24 hours in 4\% paraformaldehyde in PBS ( $\mathrm{pH} 7.4$ ). Paraffin sections ( $7 \mu \mathrm{m}$ thick) were obtained separately from 3 levels of each pancreas (head, middle, and tail) and stained for insulin (Dako Canada) (catalog IR00261-2). Insulin-immunostained sections were scanned using a Mirax Slide Scanner (Carl Zeiss) and analyzed with Mirax Veiwer and software from 3DHISTECH. Insulin immunostaining was calculated by an automated positive pixel count algorithm to determine total $\beta$ cell area, islet number per total pancreatic area, and islet size (6).

\section{Insulin secretion}

Perifusion assays on mouse pancreatic islets (50-70 islets per chamber) were performed as previously reported $(6,14)$ to assess biphasic GSIS. Insulin secreted was determined by RIA. AUC was determined above basal levels.

\section{TIRF microscopy imaging}

Exocytosis. The exocytosis study was performed with a Nikon TIRF microscopy system with a numerical aperture 1.49 objective as previously reported $(6,8)$. To assess exocytosis, a monolayer of $\beta$ cells was infected with Ad-NPY-EGFP, or alternatively with red-shifted NPY-tdmOrange2 (44) (gift from Sebastian Barg, Uppsala University, Sweden) and cultured for 24 to 36 hours before performing TIRF microscopy. Fusion events, indicated by abrupt brightening of NPY-EGFP (or -tdmOrange2) fluorescence, were manually selected, analyzed, and categorized into predocked (docked on PM at basal, then fuses after stimulation) and newcomer SGs (not predocked on PM at basal), the latter divided into short-dock (short residence time of $>200$ milliseconds at the PM) or no-dock (<200 milliseconds at the PM, which is the interval of 1 frame).

Single-molecule imaging. For single-molecule imaging experiments, INS-832/13 cells seeded onto 25 -mm coverslips were transiently transfected with $0.2 \mu \mathrm{g}$ plasmid DNA (SNAP25-mScarlet) with Lipofectamine 2000 (Life Technologies) for 3-5 hours before imaging to control the expression to a single-molecule level as shown in Supplemental Figure 10. This TIRF microscopy system is built on a commercial inverted 
Olympus IX81 frame equipped with a UAPON 150× Oil NA 1.45 objective and Hamamatsu C9100-13 EM-CCD. Olympus cellTIRF software controlled the incident angles, and images were acquired by Volocity software. For the data analysis, the sum of SNAP25/ $\mathrm{Ca}_{\mathrm{v}} 1.2$ binding time or events during the stimulation time was calculated, and then normalized to the number of $\mathrm{Ca}_{\mathrm{v}} 1.2$ clusters.

Generation of SNAP23-KO and -knockin INS-832/13. CRISPR/Cas9 SNAP23-KO and -knockin INS$832 / 13$ cells were generated according to the methods described by Sakuma et al. (54). After transfection of gRNA and Cas9, single clones were picked up and seeded into 96-well plates. For characterization of derived clones, PCR was used to preliminarily screen the targeted clones, amplifying the target site and examine the band shifts, and Western blot was used to identify the derived clones. We used same clone-derived knockin/-out cell lines for imaging to minimize the heterogeneity. These CRISPR clones were also verified by the coexpressed fluorophore mTagBFP2 or mNeonGreen as shown in Figure 9A. The sgRNA target sites and success of this strategy are described in Supplemental Figure 9.

\section{Structured illumination microscopy}

This study was performed with the Zeiss Elyra PS1 microscopy system equipped with a 100× Oil NA 1.46 objective and Andor iX3 885 detector. Human $\beta$ cells (control or SNAP23-KD condition) were stimulated with $16.7 \mathrm{mM}$ glucose plus $10 \mathrm{nM}$ GLP-1 for 10 minutes and then fixed. Endogenous SNAP25 was labeled with Alex Fluor 488 and Stx-1A/Stx-3 were labeled with Alex Fluor 647. Images were acquired by Zeiss Zen 2012 software. Pearson's correlation coefficient (PCC) calculation was performed with the Volocity software (25). The PCC value varied from -1 to 1 , whereby -1 means $100 \%$ no colocalization and 1 means perfect colocalization.

\section{Patch-clamp Cm measurements}

This was performed as previously described (55). Patch electrodes were pulled from 1.5-mm thinwalled borosilicate glass, coated close to the tip with orthodontic wax (Butler), and polished to a tip resistance of 2-3 M $\Omega$ when filled with intracellular solution. For measurement of $\mathrm{Cm}$, the intracellular solution contained (in mM): 125 cesium glutamate, $10 \mathrm{CsCl}, 10 \mathrm{NaCl}, 1 \mathrm{MgCl}_{2}, 5 \mathrm{HEPES}, 0.05$ EGTA, 3 MgATP, and 0.1 cAMP (pH 7.2). The extracellular solution consisted of (in mM): $118 \mathrm{NaCl}$, $5.6 \mathrm{KCl}, 1.2 \mathrm{MgCl}_{2}, 10 \mathrm{CaCl}_{2}, 20$ tetraethylammonium chloride, $5 \mathrm{HEPES}$, and 5 D-glucose (pH 7.4). $\mathrm{Cm}$ was estimated by the Lindau-Neher technique, implementing the Sine-DC feature of the Lock-in module (40 mV peak-to-peak and a frequency of $1 \mathrm{kHz}$ ) in the whole-cell configuration. Recordings were conducted using an EPC10 patch-clamp amplifier equipped with Pulse and X-chart software programs (HEKA Electronik). Mouse and human $\beta$ cells were identified using parameters previously described $(56,57)$. Exocytic events were elicited by a train of ten 500 -ms depolarization pulses from $-70 \mathrm{mV}$ to $0 \mathrm{mV}$. All recordings were performed at $30^{\circ} \mathrm{C}$.

\section{Photolysis of caged $\mathrm{Ca}^{2+}$ and Cm measurements}

Standard bath solution for the flash photolysis experiments contained (in $\mathrm{mM}$ ): $138 \mathrm{NaCl}, 5.6 \mathrm{KCl}$, $1.2 \mathrm{MgCl}_{2}, 2.6 \mathrm{CaCl}_{2}, 5$ glucose, 5 HEPES ( $\mathrm{pH} 7.4$ with $\mathrm{NaOH}$ ). Intracellular solution for flash experiments (in mM): 112 Cs-glutamate, 5 NP-EGTA, 3.7 CaCl, 2 Mg-ATP, $0.3 \mathrm{Na}_{2}$-GTP and 0.2 Mag-fura-2 (pH 7.2 with $\mathrm{CsOH}$ ). NP-EGTA and Mag-fura-2 were purchased from Life Technologies. [Ca ${ }^{2+}$ ] was measured using Mag-fura-2 dye, which was excited with UV illumination alternating between 340 and $380 \mathrm{~nm}$ using a monochromator-based system TILL polychrome 5000 (TILL Photonics $\mathrm{GmbH}$ ). The ratio of the fluorescence signals was converted to $\left[\mathrm{Ca}^{2+}\right]_{\mathrm{i}}$ using an in vivo calibration curve (30, 58). To obtain stepwise increases in $\left[\mathrm{Ca}^{2+}\right]_{\mathrm{i}}$, short flashes of UV light from a xenon arc flash lamp (Rapp OptoElectronics) were applied to the whole cell. Cm was measured using an EPC-10 patchclamp amplifier controlled by the Lock-in module of PULSE software. The capacitance traces were imported to IGOR Pro (WaveMetrics) for analysis.

\section{Statistics}

All data are presented either as means \pm SEM with individual plots or as box-and-whisker plots. Statistical significance was assessed by repeated-measure ANOVA, or 2-tailed Student's $t$ test in SigmaStat (Systat Software). Significant differences are indicated by asterisks. ${ }^{*} P<0.05 ;{ }^{*} P<0.01 ;{ }^{* * *} P<0.001$; NS, not significant. 


\section{Study approval}

Animals were cared for and housed in the animal facility in the University of Toronto in accordance with the Canadian Council on Animal Care Standards and the Animals for Research Act of Ontario. All animal procedures were performed under appropriate project protocols that were approved by the University of Toronto Faculties of Medicine and Pharmacy Animal Care and Ethics Committee. Human islets were isolated and provided by IsletCore (P. MacDonald) of the University of Alberta, Canada, and their use was approved by Institutional Review Board of the University of Toronto.

\section{Author contributions}

All the authors contributed to the conception and design of the study, acquisition of data (contributed most by $\mathrm{TL}, \mathrm{TQ}$, and $\mathrm{FK}$ ), and analysis and interpretation of data, as well as drafting of the article and revising it critically for important intellectual content. All authors approved the final version to be published.

\section{Acknowledgments}

This work was supported by grants to HYG from the Canadian Institute of Health Research (MOP 86544 and PJT-159741). Some of the equipment used in this study was supported by the 3D (Diet, Digestive Tract and Disease) Centre funded by the Canadian Foundation for Innovation and Ontario Research Fund, project number 19442.

Address correspondence to: Herbert Y. Gaisano, Room 7342, Medical Sciences Building, 1 King's College Circle, Toronto, Ontario M5S 1A8, Canada. Phone: 416.978.1526; Email: herbert.gaisano@utoronto.ca.

1. Südhof TC, Rothman JE. Membrane fusion: grappling with SNARE and SM proteins. Science. 2009;323(5913):474-477.

2. Gaisano HY. Here come the newcomer granules, better late than never. Trends Endocrinol Metab. 2014;25(8):381-388

3. Gaisano HY. Deploying insulin granule-granule fusion to rescue deficient insulin secretion in diabetes. Diabetologia. 2012;55(4):877-880

4. Jewell JL, Oh E, Thurmond DC. Exocytosis mechanisms underlying insulin release and glucose uptake: conserved roles for Munc18c and syntaxin 4. Am J Physiol Regul Integr Comp Physiol. 2010;298(3):R517-R531.

5. Wheeler MB, et al. Characterization of SNARE protein expression in beta cell lines and pancreatic islets. Endocrinology. 1996;137(4):1340-1348.

6. Zhu D, et al. Dual role of VAMP8 in regulating insulin exocytosis and islet $\beta$ cell growth. Cell Metab. 2012;16(2):238-249.

7. Ohara-Imaizumi $\mathrm{M}$, et al. Imaging analysis reveals mechanistic differences between first- and second-phase insulin exocytosis. J Cell Biol. 2007;177(4):695-705.

8. Zhu D, et al. Syntaxin-3 regulates newcomer insulin granule exocytosis and compound fusion in pancreatic beta cells. Diabetologia. 2013;56(2):359-369.

9. Spurlin BA, Thurmond DC. Syntaxin 4 facilitates biphasic glucose-stimulated insulin secretion from pancreatic beta-cells. Mol Endocrinol. 2006;20(1):183-193.

10. Huang X, et al. Truncated SNAP-25 (1-197), like botulinum neurotoxin A, can inhibit insulin secretion from HIT-T15 insulinoma cells. Mol Endocrinol. 1998;12(7):1060-1070.

11. Sadoul K, et al. SNAP-25 is expressed in islets of Langerhans and is involved in insulin release. J Cell Biol. 1995;128(6):1019-1028.

12. Takahashi N, et al. Sequential exocytosis of insulin granules is associated with redistribution of SNAP25. J Cell Biol. 2004;165(2):255-262.

13. Kawaguchi T, et al. The t-SNAREs syntaxin4 and SNAP23 but not v-SNARE VAMP2 are indispensable to tether GLUT4 vesicles at the plasma membrane in adipocyte. Biochem Biophys Res Commun. 2010;391(3):1336-1341.

14. Huang X, Sheu L, Tamori Y, Trimble WS, Gaisano HY. Cholecystokinin-regulated exocytosis in rat pancreatic acinar cells is inhibited by a C-terminus truncated mutant of SNAP-23. Pancreas. 2001;23(2):125-133.

15. Cosen-Binker LI, Binker MG, Wang CC, Hong W, Gaisano HY. VAMP8 is the v-SNARE that mediates basolateral exocytosis in a mouse model of alcoholic pancreatitis. J Clin Invest. 2008;118(7):2535-2551.

16. Sadoul K, et al. SNAP-23 is not cleaved by botulinum neurotoxin E and can replace SNAP-25 in the process of insulin secretion. J Biol Chem. 1997;272(52):33023-33027.

17. Munc18b is a major mediator of insulin exocytosis in rat pancreatic $\beta$-cells. Diabetes. 2013;62(7):2416-2428.

18. Salaün C, Gould GW, Chamberlain LH. Lipid raft association of SNARE proteins regulates exocytosis in PC12 cells. J Biol Chem. 2005;280(20):19449-19453.

19. Chieregatti E, Chicka MC, Chapman ER, Baldini G. SNAP-23 functions in docking/fusion of granules at low $\mathrm{Ca}^{2+}$. Mol Biol Cell. 2004;15(4):1918-1930.

20. Bhalla A, Chicka MC, Chapman ER. Analysis of the synaptotagmin family during reconstituted membrane fusion. Uncovering a class of inhibitory isoforms. J Biol Chem. 2008;283(31):21799-21807.

21. Sørensen JB, et al. Differential control of the releasable vesicle pools by SNAP-25 splice variants and SNAP-23. Cell. 2003;114(1):75-86.

22. Varlamov O, et al. i-SNAREs: inhibitory SNAREs that fine-tune the specificity of membrane fusion. J Cell Biol. 2004;164(1):79-88

23. Wiser O, et al. The voltage sensitive Lc-type $\mathrm{Ca}^{2+}$ channel is functionally coupled to the exocytotic machinery. Proc Natl Acad Sci 
USA. 1999;96(1):248-253.

24. Feng D, et al. SNAP23 regulates BAX-dependent adipocyte programmed cell death independently of canonical macroautophagy. J Clin Invest. 2018;128(9):3941-3956.

25. Liang T, et al. New roles of syntaxin-1A in insulin granule exocytosis and replenishment. J Biol Chem. 2017;292(6):2203-2216

26. Gaddy DF, Riedel MJ, Bertera S, Kieffer TJ, Robbins PD. dsAAV8-mediated gene transfer and $\beta$-cell expression of IL-4 and $\beta$-cell growth factors are capable of reversing early-onset diabetes in NOD mice. Gene Ther. 2012;19(8):791-799.

27. Wicksteed B, et al. Conditional gene targeting in mouse pancreatic $\beta$-cells: analysis of ectopic Cre transgene expression in the brain. Diabetes. 2010;59(12):3090-3098.

28. Rorsman P, Renström E. Insulin granule dynamics in pancreatic beta cells. Diabetologia. 2003;46(8):1029-1045.

29. Condliffe SB, Corradini I, Pozzi D, Verderio C, Matteoli M. Endogenous SNAP-25 regulates native voltage-gated calcium channels in glutamatergic neurons. J Biol Chem. 2010;285(32):24968-24976.

30. Yang Y, Udayasankar S, Dunning J, Chen P, Gillis KD. A highly $\mathrm{Ca}^{2+}$-sensitive pool of vesicles is regulated by protein kinase C in adrenal chromaffin cells. Proc Natl Acad Sci USA. 2002;99(26):17060-17065.

31. Ostenson CG, Gaisano H, Sheu L, Tibell A, Bartfai T. Impaired gene and protein expression of exocytotic soluble N-ethylmaleimide attachment protein receptor complex proteins in pancreatic islets of type 2 diabetic patients. Diabetes. 2006;55(2):435-440

32. Qin T, et al. Munc18b increases insulin granule fusion, restoring deficient insulin secretion in type-2 diabetes human and Goto-Kakizaki rat islets with improvement in glucose homeostasis. EBioMedicine. 2017;16:262-274

33. Ostenson CG, Efendic S. Islet gene expression and function in type 2 diabetes; studies in the Goto-Kakizaki rat and humans. Diabetes Obes Metab. 2007;9 Suppl 2:180-186.

34. Gaisano HY, Ostenson CG, Sheu L, Wheeler MB, Efendic S. Abnormal expression of pancreatic islet exocytotic soluble N-ethylmaleimide-sensitive factor attachment protein receptors in Goto-Kakizaki rats is partially restored by phlorizin treatment and accentuated by high glucose treatment. Endocrinology. 2002;143(11):4218-4226.

35. Banks K, Qin T, Liang T, Wang AJ, Gaisano HY. Biliopancreatic route for effective viral transduction of pancreatic islets. Pancreas. 2014;43(2):240-244

36. Kawai J, et al. Insulin exocytosis in Goto-Kakizaki rat beta-cells subjected to long-term glinide or sulfonylurea treatment. Biochem J. 2008;412(1):93-101.

37. Zhu D, et al. Syntaxin 2 acts as inhibitory SNARE for insulin granule exocytosis. Diabetes. 2017;66(4):948-959.

38. Yasuda T, et al. Rim2alpha determines docking and priming states in insulin granule exocytosis. Cell Metab. 2010;12(2):117-129.

39. Shibasaki T, Sunaga Y, Fujimoto K, Kashima Y, Seino S. Interaction of ATP sensor, cAMP sensor, $\mathrm{Ca}^{2+}$ sensor, and voltage-dependent $\mathrm{Ca}^{2+}$ channel in insulin granule exocytosis. J Biol Chem. 2004;279(9):7956-7961.

40. Xie L, Zhu D, Gaisano HY. Role of mammalian homologue of Caenorhabditis elegans unc-13-1 (Munc13-1) in the recruitment of newcomer insulin granules in both first and second phases of glucose-stimulated insulin secretion in mouse islets. Diabetologia. 2012;55(10):2693-2702.

41. Gandasi NR, et al. $\mathrm{Ca}^{2+}$ channel clustering with insulin-containing granules is disturbed in type 2 diabetes. J Clin Invest. 2017;127(6):2353-2364

42. Gustavsson N, et al. Impaired insulin secretion and glucose intolerance in synaptotagmin-7 null mutant mice. Proc Natl Acad Sci USA. 2008;105(10):3992-3997.

43. Dolai S, et al. Synaptotagmin-7 functions to replenish insulin granules for exocytosis in human islet $\beta$-cells. Diabetes. 2016;65(7):1962-1976.

44. Gandasi NR, Vestö K, Helou M, Yin P, Saras J, Barg S. Survey of red fluorescence proteins as markers for secretory granule exocytosis. PLoS ONE. 2015;10(6):e0127801

45. Suh YH, et al. A neuronal role for SNAP-23 in postsynaptic glutamate receptor trafficking. Nat Neurosci. 2010;13(3):338-343.

46. Delgado-Martínez I, Nehring RB, Sørensen JB. Differential abilities of SNAP-25 homologs to support neuronal function. J Neurosci. 2007;27(35):9380-9391.

47. Weber JP, Toft-Bertelsen TL, Mohrmann R, Delgado-Martinez I, Sørensen JB. Synaptotagmin-7 is an asynchronous calcium sensor for synaptic transmission in neurons expressing SNAP-23. PLoS ONE. 2014;9(11):e114033.

48. Geppert M, et al. Synaptotagmin I: a major $\mathrm{Ca}^{2+}$ sensor for transmitter release at a central synapse. Cell. 1994;79(4):717-727.

49. Kunii M, et al. Opposing roles for SNAP23 in secretion in exocrine and endocrine pancreatic cells. J Cell Biol. 2016;215(1):121-138

50. Xie L, et al. Syntaxin-4 mediates exocytosis of pre-docked and newcomer insulin granules underlying biphasic glucose-stimulated insulin secretion in human pancreatic beta cells. Diabetologia. 2015;58(6):1250-1259.

51. Bender E. Gene therapy: Industrial strength. Nature. 2016;537(7619):S57-S59.

52. Pasyk EA, Kang Y, Huang X, Cui N, Sheu L, Gaisano HY. Syntaxin-1A binds the nucleotide-binding folds of sulphonylurea receptor 1 to regulate the KATP channel. J Biol Chem. 2004;279(6):4234-4240.

53. Akimoto Y, Sawada H, Ohara-Imaizumi M, Nagamatsu S, Kawakami H. Change in long-spacing collagen in Descemet's membrane of diabetic Goto-Kakizaki rats and its suppression by antidiabetic agents. Exp Diabetes Res. 2008;2008:818341.

54. Sakuma T, Nakade S, Sakane Y, Suzuki KT, Yamamoto T. MMEJ-assisted gene knock-in using TALENs and CRISPR-Cas 9 with the PITCh systems. Nat Protoc. 2016;11(1):118-133.

55. Xie L, Zhu D, Kang Y, Liang T, He Y, Gaisano HY. Exocyst sec5 regulates exocytosis of newcomer insulin granules underlying biphasic insulin secretion. PLoS ONE. 2013;8(7):e67561.

56. Göpel S, Kanno T, Barg S, Galvanovskis J, Rorsman P. Voltage-gated and resting membrane currents recorded from B-cells in intact mouse pancreatic islets. J Physiol (Lond). 1999;521 Pt 3:717-728.

57. Braun M, et al. Voltage-gated ion channels in human pancreatic beta-cells: electrophysiological characterization and role in insulin secretion. Diabetes. 2008;57(6):1618-1628.

58. Wan QF, Dong Y, Yang H, Lou X, Ding J, Xu T. Protein kinase activation increases insulin secretion by sensitizing the secretory machinery to $\mathrm{Ca}^{2+} . J$ Gen Physiol. 2004;124(6):653-662. 